\title{
Intraspecific variation in tolerance of warming in fishes
}

\author{
David J. McKenzie $^{1}$ (1) | Yangfan Zhang ${ }^{2}$ | Erika J. Eliason ${ }^{3}$ | Patricia M. Schulte ${ }^{2}$ | \\ Guy Claireaux $^{4}$ | Felipe R. Blasco ${ }^{5,6}$ | Julie J.H Nati ${ }^{1}$ | Anthony P. Farrell ${ }^{2,7}$
}

${ }^{1}$ MARBEC, University of Montpellier, CNRS, IFREMER, IRD, Montpellier, France

${ }^{2}$ Department of Zoology, University of British Columbia, Vancouver, British Columbia,

Canada

${ }^{3}$ UC Santa Barbara, Santa Barbara, California

${ }^{4}$ Université de Bretagne Occidentale, LEMAR (UMR 6539), Centre Ifremer de Bretagne,

Plouzané, France

${ }^{5}$ Department of Physiological Sciences, Federal University of São Carlos, São Carlos, Brazil

${ }^{6}$ Joint Graduate Program in Physiological Sciences, Federal University of São Carlos UFSCar/São Paulo State University, UNESP Campus Araraquara, Araraquara, Brazil

${ }^{7}$ Faculty of Land and Food Systems, University of British Columbia, Vancouver, British

Columbia, Canada

\section{Correspondence}

David J. McKenzie, MARBEC, University of Montpellier, CNRS, IFREMER, IRD,

Montpellier, France.

Email: david.mckenzie@cnrs.fr

Funding information

Coordenação de Aperfeiçoamento de Pessoal de Nível Superior; Elizabeth R. Howland Fellowship; EU Marie-Curie Individual Fellowship, Grant/Award Number: 839039; George Weston Ltd. Doctoral Fellowship; Hellman Fellows Fund; Natural Sciences and Engineering Research Council of Canada (NSERC)

\begin{abstract}
Intraspecific variation in key traits such as tolerance of warming can have profound effects on ecological and evolutionary processes, notably responses to climate change. The empirical evidence for three primary elements of intraspecific variation in tolerance of warming in fishes is reviewed. The first is purely mechanistic that tolerance varies across life stages and as fishes become mature. The limited evidence indicates strongly that this is the case, possibly because of universal physiological principles. The second is intraspecific variation that is because of phenotypic plasticity, also a mechanistic phenomenon that buffers individuals' sensitivity to negative impacts of global warming in their lifetime, or to some extent through epigenetic effects over successive generations. Although the evidence for plasticity in tolerance to warming is extensive, more work is required to understand underlying mechanisms and to reveal whether there are general patterns. The third element is intraspecific variation based on heritable genetic differences in tolerance, which underlies local adaptation and may define long-term adaptability of a species in the face of ongoing global change. There is clear evidence of local adaptation and some evidence of heritability of tolerance to warming, but the knowledge base is limited with detailed information for only a few model or emblematic species. There is also strong evidence of structured variation in tolerance of warming within species, which may have ecological and evolutionary significance irrespective of whether it reflects plasticity or adaptation. Although the overwhelming consensus is that having broader intraspecific variation in tolerance should reduce species vulnerability to impacts of global warming, there are no sufficient data on fishes to provide insights into particular mechanisms by which this may occur.
\end{abstract}

\section{KEYWORDS}

adaptation, critical thermal maximum, phenotypic plasticity, size effects, thermal performance curve, vulnerability

\section{1 | INTRODUCTION}

Current models of global warming predict increases in seasonal temperatures by up to $4^{\circ} \mathrm{C}$ by 2100 , along with an increase in the frequency of localized acute and extreme warming events (Collins \& Sutherland, 2019; Frölicher \& Laufkötter, 2018; IPCC, 2014). These changes are likely to cause population declines, local extirpation or even extinction when species characteristics are poorly suited to the novel environments (Bennett et al., 2019; Burggren, 2019; Pacifici et al., 2015). Fishes may be especially vulnerable to global warming because, as ectotherms, their physiology is determined by thermodynamic effects of the surrounding water temperature, which sets their 
body temperature (Cossins \& Bowler, 1987; Currie \& Schulte, 2014; Fry, 1971; Schulte, 2011). General principles of the thermal physiology of fishes and their responses to water temperature and thermal stress have been widely reviewed (e.g., Cossins \& Bowler, 1987; Currie \& Schulte, 2014; Little et al., 2020), and therefore they are not revisited here. Instead, the authors of this study focus on intraspecific variation in tolerance of warming and its significance for predicting species' responses to climate change.

Intraspecific variation exists both within and among individuals and populations of a species (Bolnick et al., 2011; Killen et al., 2016a; Mimura et al., 2017; Spicer \& Gaston, 2000). One element of withinindividual variation refers to ontological and physiological changes that occur across life stages and with body size, such that particular life stages may be weak links in overall species sensitivity (Dahlke et al., 2020; Pörtner \& Peck, 2010; Righton et al., 2010). A second element is phenotypic plasticity, the ability of a given genotype to produce different phenotypes in response to the environment within an individual's lifetime (Stearns, 1989), which can be a source of variation both within and among individuals. A capacity for plasticity in tolerance can buffer against the immediate impacts of thermal stress, thereby reducing population sensitivity. Thirdly, there is genetically based heritable variation among individuals, either within or between populations. Possessing a broad range of heritable tolerance genotypes will influence population adaptability and the capacity to adjust to new conditions over generational time scales (Bennett et al., 2019; Moran et al., 2016; Pacifici et al., 2015). These collective effects of individual variation in thermal tolerance can, therefore, have important implications for vulnerability of populations and species to both short-term extreme heatwaves and long-term gradual warming (Bennett et al., 2019). This then has far-reaching consequences. If broad functional variation among individuals increases the stability and resilience of a species in the face of environmental stressors, such as warming, this can stabilize the species' ecological functions and, in turn, stabilize overall community and ecosystem function (Bolnick et al., 2011; Mimura et al., 2017; Pacifici et al., 2015).

\section{I HOW TO MEASURE TOLERANCE OF WARMING}

Before the nature and extent of these three types of intraspecific variation in thermal tolerance in fishes are considered, how tolerance is typically measured should be briefly reviewed. The methods for assessing thermal tolerance in fishes are well established (Cossins \& Bowler, 1987; Currie \& Schulte, 2014; Lutterschmidt \& Hutchison, 1997; Schulte et al., 2011), and only a brief summary is provided here, for the convenience of the reader. The Fry thermal tolerance polygon (Fry-TTP, Figure 1) is the standard framework to display tolerance boundaries in fishes and how these are influenced by acclimatization (or more often acclimation) to temperatures across a species' natural range (Cossins \& Bowler, 1987; Currie \& Schulte, 2014). The Fry-TTP boundaries are measured using acute thermal ramping protocols, especially the

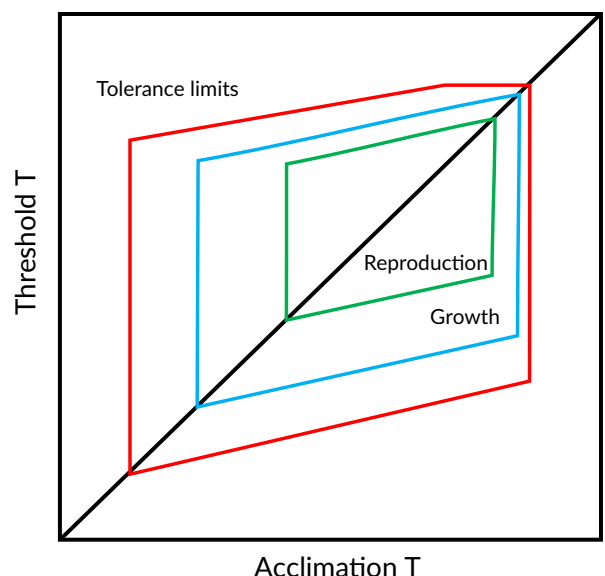

FIGURE 1 Fry thermal tolerance polygon. The polygon is bounded by the minimum and maximum temperatures that can be tolerated for a relatively short period of time before they threaten life (outer red polygon). Boundaries are measured using acute thermal ramping protocols. In particular, the critical thermal (CT) protocol where a fish is progressively heated for the $\mathrm{CT}$ maximum $\left(\mathrm{CT}_{\max }\right)$ or cooled for the $\mathrm{CT}$ minimum $\left(\mathrm{CT}_{\mathrm{min}}\right)$ until it exhibits a loss of equilibrium (LOE) (Beitinger \& Lutterschmidt, 2011; Lutterschmidt \& Hutchison, 1997). The critical threshold temperature for fatigue from swimming $\left(\mathrm{CT}_{\text {swim }}\right)$ is an alternative and potentially more ecologically relevant protocol. It involves imposing a fixed level of steady and sustained aerobic exercise upon a fish, in a swim flume, then warming (or cooling) the fish in steps until it fatigues (Blasco et al., 2020b; Steinhausen et al., 2008). Maximum $\mathrm{CT}_{\text {swim }}$ occurs at a lower temperature than $\mathrm{CT}_{\max }$ (Blasco et al., 2020b) so a Fry-TTP derived with a $\mathrm{CT}_{\text {swim }}$ protocol would lie inside of one derived by classic $\mathrm{CT}$ protocol. These two boundary temperatures delineate the absolute range of thermal tolerance for a given acclimation temperature, and by making similar determinations as fishes are acclimated in the laboratory (or acclimatized in nature) to temperatures over their natural thermal range, the Fry-TTP also displays how these boundaries change by phenotypic plasticity. The inner polygons denote the temperature limits for major components of fitness such as growth (blue) and reproduction (green) (Brett, 1971). These are typically inferred from thermal performance curves that measure rate functions such as growth or, most commonly, aerobic scope over a range of acclimation temperatures (Figure 2)

critical thermal (CT) methodology that uses loss of equilibrium (LOE) as tolerance endpoint (Figure 1). The protocol is simple and defines the temperature where survival is threatened because at LOE the fish cannot escape the conditions (Beitinger \& Lutterschmidt, 2011). An alternative is the critical threshold temperature for fatigue from swimming $\left(\mathrm{CT}_{\text {swim }}\right)$, which may have greater ecological relevance because it defines the temperature where fish can no longer perform an ecologically essential activity (Figure 1), but this protocol has not yet been applied widely (Blasco et al., 2020b). Lying inside a Fry-TTP are more restricted zones (Figure 1) that are delimited by temperature-dependent effects on the performance of activities that are essential for growth and reproduction (Brett, 1971; Cossins \& Bowler, 1987; Currie \& Schulte, 2014; Schulte et al., 2011). 


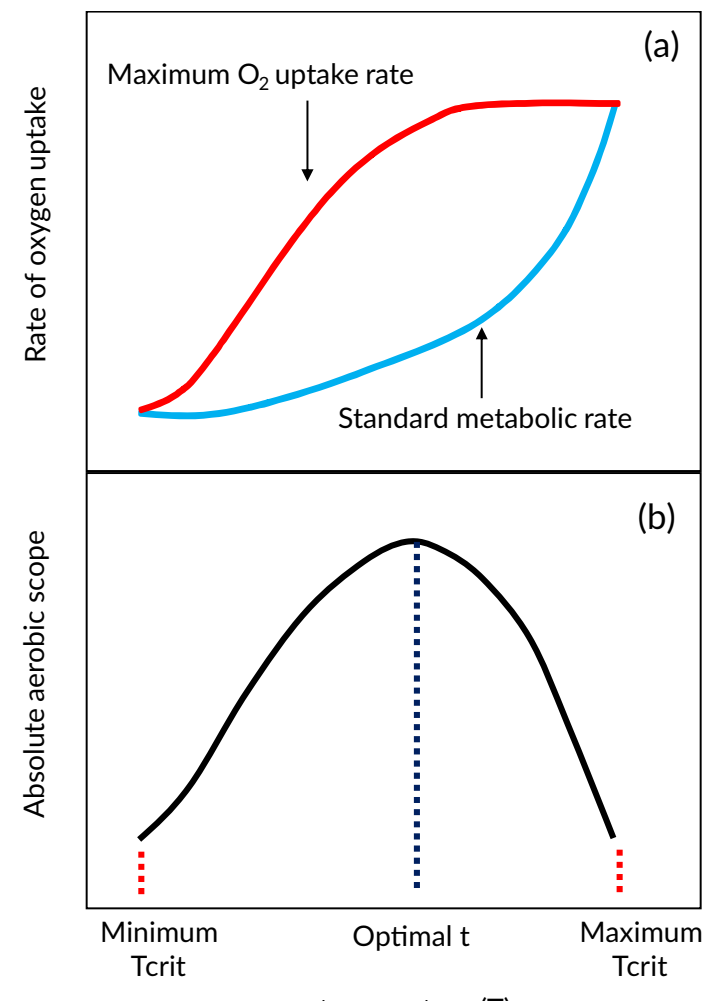

temperature $(\mathrm{T})$

FIGURE 2 The Fry paradigm and how it describes a thermal performance curve (TPC) for absolute aerobic scope (AAS) in fishes. To develop a TPC for AAS, fish are exposed (whether acutely, acclimated or acclimatized) to a range of temperatures and their standard metabolic rate (SMR, the basal metabolic rate at the prevailing temperature) and maximum metabolic rate (MMR, the maximum capacity for oxygen uptake at that temperature) are measured by respirometry. The AAS is the net difference between SMR and MMR (MMR-SMR) (Claireaux et al., 2006; Eliason et al., 2011; Fry, 1971; Schulte, 2015) and represents the capacity to provide oxygen for all energetic fluxes such as swimming exercise and so forth. Nonetheless, many studies replace SMR with a slightly higher routine metabolic rate (RMR) where there is some contribution to metabolic rate from routine activity (Lefevre, 2016). The theoretical basis of the Fry paradigm is that temperature controls all metabolic processes in ectothermic fishes. In (a), the blue line shows how SMR (or RMR) and MMR vary as a function of water temperature and resultant effects on AAS. The SMR is expected to increase exponentially with temperature because of direct thermodynamic effects on all respiring body tissues. At low temperatures MMR is also low, because the cold inhibits all processes that underlie performance, so AAS is small. As temperatures rise, AAS increases because warming accelerates all metabolic processes and provides for increased MMR and performance. Nonetheless, eventually the effects of temperature on SMR make it rise to the point where it coincides with the fish's absolute maximum capacity for oxygen uptake, so AAS is again very small. The resultant AAS is shown in (b), with a clear optimal temperature $\left(T_{\text {opt }}\right)$ where AAS is greatest and critical thermal limits $\left(T_{\text {crit }}\right)$ where AAS is zero. Various researchers define an optimal range of AAS based on the temperatures where it is, e.g., at least $90 \%$ of the maximum AAS at $T_{\text {opt }}$. TPCs for AAS are time-consuming and labourintensive to develop. A cardiac TPC can be generated much faster by measuring heart rate $\left(f_{\mathrm{H}}\right)$ from the ECG of anaesthetised fish that have been pharmacologically treated to abolish all autonomic control
These inner zones are typically defined with a thermal performance curve (TPC) that measures a trait of organismal performance over a range of temperatures. A TPC can then identify a thermal optimum, the thermal range over which performance is near to optimal (thermal breadth), and temperature thresholds for alterations in performance (Figure 1) (Currie \& Schulte, 2014; Pörtner et al., 2010; Schulte et al., 2011; Wang \& Overgaard, 2007). The prevailing theories for what defines thermal tolerance in fishes, the Fry Paradigm (Fry, 1947, 1957, 1971) and the oxygen and capacity-limited thermal tolerance (OCLTT) hypothesis (Pörtner, 2010), both focus on fish cardiorespiratory physiology and the capacity to meet the oxygen requirements of aerobic metabolism when a fish is subjected to the thermodynamic effects of water temperature (Figure 2). The most common TPC is, therefore, for absolute aerobic scope (AAS), which measures how much a fish can raise its rate of oxygen uptake above standard metabolic rate (SMR, the basal metabolic rate at acclimation temperature) to reach its maximum metabolic rate (MMR, the maximum capacity for oxygen uptake at that temperature) (Fry, 1971; Claireaux et al., 2006; Eliason et al., 2011; Schulte, 2015; explained in Figure 2). The AAS is proposed to be of ecological significance because it defines the upper limit for oxygen allocation by a fish to sustain aerobic activities such as foraging, digestion, tissue deposition, migration, reproduction (Claireaux \& Lefrançois, 2007; Farrell, 2009; Fry, 1971; Pörtner, 2010; Schulte, 2015).

The Fry paradigm and OCLTT hypothesis predict a unimodal curve where AAS rises as a fish is warmed towards its optimal temperature ( $\left.T_{\text {opt }}\right)$, followed by a rather steep decline after $T_{\text {opt }}$ is exceeded and the animal approaches its critical upper thermal tolerance limit ( $T_{\text {crit }}$, Figure 2$)$. The authors describe the Fry paradigm and OCLTT hypothesis here because they are the reason that so many studies have used a TPC for AAS to investigate the effects of temperature on fish performance (see below). In fact, many fish species do not exhibit a unimodal TPC for AAS with a clear $T_{\text {opt }}$ (Lefevre, 2016) and, most notably, many show no decline in AAS as they are warmed towards their upper thermal tolerance limit (Gräns et al., 2014; Lefevre, 2016; Norin et al., 2014; Poletto et al., 2017; Verhille et al., 2016). That is, based on the available evidence, the Fry paradigm and OCLTT cannot be assumed to be universal principles and are currently a topic of debate in the literature (Clark et al., 2013; Farrell, 2016; Jutfelt et al., 2018; Pörtner et al., 2017).

The fish heart assures oxygen delivery to all tissues in response to their demands, so cardiac performance is considered a central

and then incrementally warmed to follow the response of maximum heart rate $\left(f_{\mathrm{H} \max }\right)$ (Anttila et al., 2013; Casselman et al., 2012; Chen et al., 2015; Ferreira et al., 2014). This can reveal thresholds for $f_{H}$ that closely parallel those of AAS with temperature, i.e., the Arrhenius break temperature $\left(T_{\mathrm{AB}}\right)$ when $f_{\mathrm{H} \text { max }}$ is reaching its upper asymptote, which coincides closely with $T_{\text {opt }}$ for AAS. Beyond that, the warm temperature that triggers cardiac arrhythmia $\left(T_{\text {arr }}\right)$ coincides closely with $T_{\text {crit }}$ (Anttila et al., 2013; Casselman et al., 2012; Chen et al., 2015; Ferreira et al., 2014) 
mechanism determining upper thermal tolerance in fishes (Eliason \& Anttila, 2017; Farrell, 2009). TPCs for cardiac performance have been generated for various fish species (Anttila et al., 2013; Casselman et al., 2012; Chen et al., 2015; Ferreira et al., 2014), defining a series of threshold temperatures for performance and tolerance of the heart such as the Arrhenius break temperature $\left(T_{A B}\right)$ and the temperature that triggers cardiac arrhythmia $\left(T_{\text {arr }}\right)$. In the species studied to date, these cardiac thresholds are correlated with $T_{\text {opt }}$ and upper $T_{\text {crit }}$ for AAS, respectively (Casselman et al., 2012; Anttila et al., 2013; Ferreira et al., 2014; Chen et al., 2015, see Figure 2). The approach has a number of advantages over a TPC for AAS, in particular that its relatively rapid and easy easy to apply to wild fish under field conditions and the data can be used to develop Fry-TTPs (Chen et al., 2015; Drost et al., 2016).

Comprehensive Fry-TTPs that include TPCs for underlying traits have only been developed for a few fish species (Brett, 1971; Currie \& Schulte, 2014; Ferreira et al., 2014). Nonetheless, CT maximum $\left(\mathrm{CT}_{\max }\right)$ and minimum $\left(\mathrm{CT}_{\min }\right)$ have been used to interpret global warming impacts on fishes, such as range shifts (Sunday et al., 2011) or vulnerability to extreme warming events (Pinsky et al., 2019). Performance curves based on AAS have been used to interpret declines in species population abundance (Pörtner \& Knust, 2007), failures of reproductive migrations (Eliason et al., 2011), how optimal habitats change with warming (Deutsch et al., 2015), and why particular species may be invading new areas (Marras et al., 2015). Cardiac TPCs have yet to be applied widely but have revealed population differences and also variation within populations (Anttila et al., 2014; Chen et al., 2015). These various methodologies to measure heat tolerance have also been used to reveal considerable intraspecific variation in thermal tolerance in fishes.

\section{3 | INTRASPECIFIC VARIATION IN THERMAL TOLERANCE BECAUSE OF THE EFFECTS OF LIFE STAGE}

Life stage can have a profound effect on tolerance of warming, reflecting how the physiology of all fishes changes as they grow, from embryos to reproducing adults. A meta-analysis of thermal tolerance thresholds for 694 species (Dahlke et al., 2020) concluded that embryos and spawning adults have lower $\mathrm{CT}_{\max }$ and a narrower thermal range (the difference in ${ }^{\circ} \mathrm{C}$ between $\mathrm{CT}_{\min }$ and $\mathrm{CT}_{\max }$ ) than larvae or adults (these latter defined as all animals post-metamorphosis, so from juveniles to mature adults that are not spawning). This would indicate that the thermal tolerance of reproducing adults and their immediate offspring is a bottleneck in determining the sensitivity to ongoing global warming (Dahlke et al., 2020). Nonetheless, much of the data in this analysis were generated by the technique of phylogenetic data imputation, which is based on reconstruction of an ancestral state and missing data are then estimated by a likelihood-based phylogenetic imputation approach. That is, actual tolerance measures are only available for a sub-set of life stages in a sub-set of the 674 species (Dahlke et al., 2020). Very few studies have, in fact, directly compared tolerance thresholds across life stages. Komoroske et al. (2014) found that $\mathrm{CT}_{\max }$ was the highest in larvae and lowest in post-spawning adults of the delta smelt Hypomesus transpacificus (McAllister 1963). Drost et al. (2016) used a cardiac TPC to find that the temperature of maximum heart rate was lower in larval compared to adult Arctic cod Boreogadus saida (Lepechin 1774), indicating a lower $T_{\mathrm{opt}}$, although the life stages did not differ in their $T_{A B}$ or $T_{\text {arr }}$ (see Figure 2).

Within the larval stage, thermal tolerance may increase with age because of progressive development of physiological systems, notably the cardiorespiratory system (Wieser, 1985), and the ensuing capacity to meet metabolic challenges imposed by warming. This may be exacerbated if the metabolic costs of growth and development already require a large proportion of a larva's oxygen supply capacity, leaving little scope for anything else (Rombough, 1988). Although various studies have measured $\mathrm{CT}_{\max }$ in larvae, few have considered how tolerance is affected by larval development (Moyano et al., 2017; Illing et al., 2020). Larvae of temperate European sea bass Dicentrarchus labrax L. 1756 show increased $\mathrm{CT}_{\max }$ as they develop towards metamorphosis, and the same is true for two tropical species, cinnamon anemonefish Amphiprion melanopus Bleeker 1852 and the barramundi Lates calcarifer Bloch 1790 (Moyano et al., 2017; Illing et al., 2020). On the contrary, larvae of the herring Clupea harengus L. 1758 (temperate) and the spiny chromis damsel Acanthochromis polyacanthus Bleeker 1855 (tropical) show no change in $\mathrm{CT}_{\max }$ as they age (Moyano et al., 2017; Illing et al., 2020). Chen et al. (2013) found that $\mathrm{CT}_{\max }$ of fry from four populations of sockeye salmon Oncorhynchus nerka (Walbaum 1787) was strongly positively related to their mass. The thermal sensitivity of Antarctic ploughfish Gymnodraco acuticeps Boulenger 1902 larvae declined as they developed, measured as the $\mathrm{Q}_{10}$ temperature coefficient for oxygen uptake rate (Flynn \& Todgham, 2018). Thus, within various fish larvae and a salmonid fry, evidence provides support for a general principle whereby tolerance increases as development proceeds towards metamorphosis.

Therefore, these various studies together highlight the importance of intraspecific variation in tolerance of warming because of life stage in fishes. This intraspecific variation in tolerance to warming, and the resulting sensitivity of particular life stages, must be considered when making projections regarding the potential effects of climate change on fish species.

\section{4 | INTRASPECIFIC VARIATION IN THERMAL TOLERANCE TO BODY SIZE}

One of the major effects of global warming on fishes may be a widespread progressive decline in final adult body size in many species, which has been correlated with rising temperatures in both freshwater and marine habitats (Audzijonyte et al., 2020; Baudron et al., 2014; Daufresne et al., 2009). In laboratory studies, final adult size after rearing at different temperatures has a negative relationship with temperature, the so-called temperature-size rule (TSR, Atkinson, 1994). These phenomena, the TSR and a global decline in fish size that correlates with global warming, may reflect, at least in part, a decline in tolerance of warming as fishes increase in mass (Audzijonyte et al., 2019; Hoefnagel \& Verberk, 2015). Furthermore, although the mechanisms 


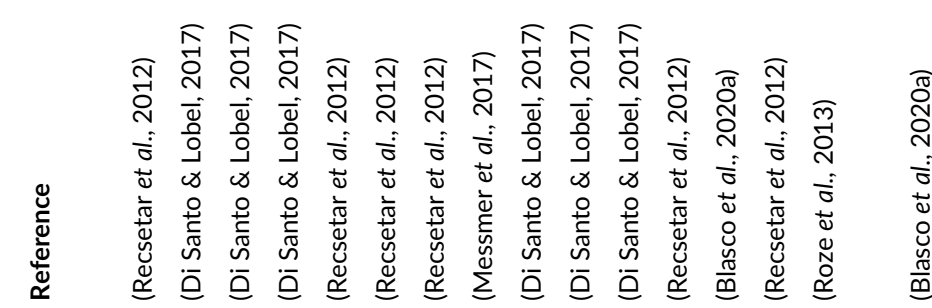

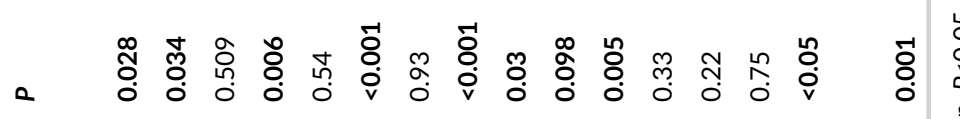

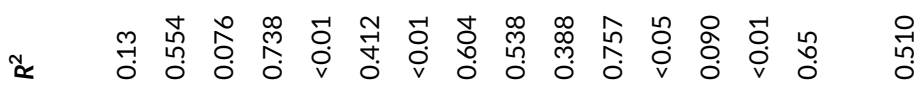

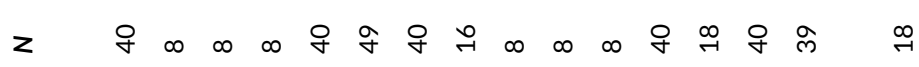

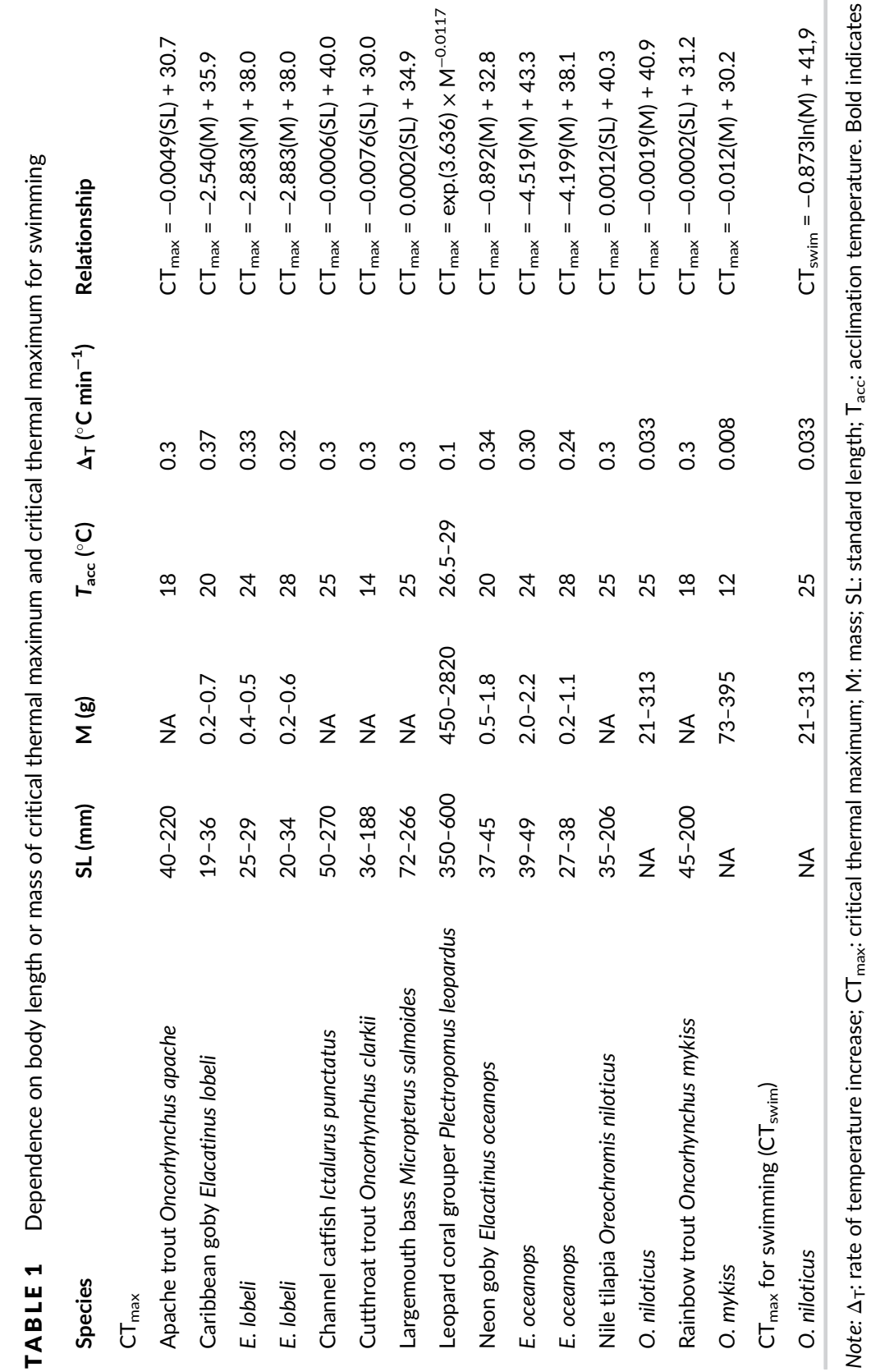


underlying the decline in adult fish size and the TSR remain to be clarified, a reduced capacity to supply oxygen to tissues in larger fishes has repeatedly been evoked (Atkinson \& Sibly, 1997; Audzijonyte et al., 2019; Cheung et al., 2011; Hoefnagel \& Verberk, 2015; Leiva et al., 2019), a possibility that should be comprehensively tested.

When comparing across fish species, $\mathrm{CT}_{\max }$ can decline with body and consequent cell size (Leiva et al., 2019). There is also evidence that, within some species, $\mathrm{CT}_{\max }$ declines with fish size or mass (Table 1). In freshwater, cutthroat trout Oncorhynchus clarkii (Richardson 1836) or apache trout Oncorhynchus apache (Miller 1872) show a very modest, albeit significant, decline with mass, whereas others such as Nile tilapia Oreochromis niloticus (L. 1758) and channel catfish Ictalurus punctatus (Rafinesque 1818) show no relationship between mass and $\mathrm{CT}_{\max }$ (Table 1; Blasco et al., 2020a; Recsetar et al., 2012). In sea water, tropical species such as Caribbean neon goby Elacatinus lobeli Randall \& Colin 2009, neon goby Elacatinus oceanops Jordan 1904 and leopard coral grouper Plectropomus leopardus (Lacipède 1802) show quite profound negative relationships between $\mathrm{CT}_{\max }$ and mass, such that larger individuals do indeed have lower acute tolerance (Table 1; Di Santo \& Lobel, 2017; Messmer et al., 2017). In marine tropical damselfishes, $\mathrm{CT}_{\max }$ declined with size in spiny chromis Acanthochromis polyacanthus Bleeker 1855 and white damsel Dischistodus perspicillatus Cuvier 1830, but not in humbug Dascyllus aruanus L. 1758 (Clark et al., 2017). In some species like rainbow trout Oncorhynchus mykiss (Walbaum 1787) results differ between studies (Table 1). For example, Recsetar et al. (2012) found no dependence, whereas, in two rainbow trout strains with either rapid or slow growth, Roze et al. (2013) found a clear negative relationship between body mass and "time to loss of equilibrium" (TLOE, measured with a ramping protocol with initial rapid steps and then in lower steps, until LOE).

Thus, with limited data, it can be concluded that whenever a relationship exists between $\mathrm{CT}_{\max }$ and size or mass in post-metamorphic fishes, it is consistently negative. It is not known how body size affects TPCs and $T_{\text {opt }}$ for AAS in fishes as they grow, although optimal temperature for growth declines with increasing body mass in various species (e.g., Björnsson \& Tryggvadóttir, 1996). In terms of whether declining size is due to problems with providing oxygen for metabolism, mass-specific MMR does in fact decline with increasing mass in many fishes due to allometric scaling phenomena whose mechanisms are still not understood (Glazier, 2020; Killen et al., 2016b; Lefevre et al., 2017). Nonetheless, because mass-specific SMR also declines with mass, AAS and capacity to perform aerobic activities are maintained independent of mass (Lefevre et al., 2017). Blasco et al. (2020a) found that $\mathrm{CT}_{\text {swim }}$ declined significantly with increasing mass in Nile tilapia (Table 1), and this was correlated with a decline in the highest rate of oxygen uptake achieved before fatigue at $\mathrm{CT}_{\text {swim }}$ (Blasco et al., 2020a). Interestingly, $\mathrm{CT}_{\max }$ showed no relationship to mass in the same individuals (Table 1 ) and was not correlated with $\mathrm{CT}_{\text {swim }}$ (Blasco et al., 2020a). Thus, tolerance of warming declines with mass in many fish species, but more research is required to establish whether this is because of a reduced capacity of larger fishes to meet the oxygen demands of metabolism when water temperature rises.
Further research is also required to understand whether this might be a mechanism underlying ongoing declines in fish body size globally (Audzijonyte et al., 2019; Blasco et al., 2020a).

Taken together, these data point to body size as another important factor that can lead to intraspecific variation in tolerance of warming in fishes. Such potential effects of fish body size, in combination with the known effects of fishing pressure on body size (van Wijk et al., 2013), should be considered when making predictions regarding the likely effects of climate warming on fish populations.

\section{5 | INTRASPECIFIC VARIATION IN THERMAL TOLERANCE DUE TO PHENOTYPIC PLASTICITY}

Phenotypic plasticity can be classified into three main types: reversible, developmental and transgenerational (Angilletta, 2009; Donelson et al., 2018). Reversible plasticity is also called acclimatization or acclimation and refers to flexible changes in physiological phenotypes as a result of environmental exposures in the time range of days to months, e.g., seasonal acclimatization in temperate fishes (Schulte et al., 2011). Developmental plasticity occurs when conditions during early development cause the expression of a phenotype that is then fixed for the remainder of the animal's lifetime. Transgenerational plasticity occurs when the environment experienced by the parent affects the phenotype of the offspring and can be mediated by epigenetic responses that affect gene expression and therefore the phenotype, but not the underlying genetic code (Donelson et al., 2018; Mimura et al., 2017; Moran et al., 2016). Epigenetic responses can contribute to immediate plastic responses but may also be heritable over a few generations (Donelson et al., 2018; Mimura et al., 2017; Moran et al., 2016). A vast majority of studies of the effects of plasticity on tolerance of warming in fish have focused on reversible phenomena, and far fewer have examined developmental or transgenerational effects.

Many studies have investigated the effects of seasonal acclimatization or acclimation on $\mathrm{CT}_{\max }$ in the laboratory (Beitinger \& Lutterschmidt, 2011; Lutterschmidt \& Hutchison, 1997). These latter effects are delineated in the Fry-TTP by the increases in thermal tolerance boundaries as temperature rises along the $x$-axis (Figure 1 ). Given that the mechanisms which underlie LOE at $\mathrm{CT}_{\max }$ in fishes are unknown, the reasons why $\mathrm{CT}_{\max }$ is plastic are also unclear but may involve a number of processes that are involved in thermal acclimation or acclimatization (Currie \& Schulte, 2014). Nonetheless, one common pattern is that a given increase in acclimation temperature is not linked to an equivalent increase in $\mathrm{CT}_{\max }$, such that the thermal safety margin, the difference between acclimation temperature and $\mathrm{CT}_{\max }$, narrows as a fish is acclimated to progressively warmer temperatures across its thermal range (e.g., Habary et al., 2017; McArley et al., 2017; McDonnell et al., 2019; Spinks et al., 2019). This effect is exemplified by an extensive data set on rainbow trout relating acclimation temperature to $\mathrm{CT}_{\max }$ (Table 2, Figure 3), where there is a clear asymptote in $\mathrm{CT}_{\max }$ as animals are acclimated to increasingly higher temperatures 
TAB LE 2 Critical thermal maximum ( $\left.\mathrm{CT}_{\max }\right)$ comparisons for various strains of Oncorhynchus mykiss under different acclimation temperatures

\begin{tabular}{|c|c|c|c|c|c|c|}
\hline$T_{\text {acclim }}\left({ }^{\circ} \mathrm{C}\right)$ & $\mathrm{CT}_{\max }\left({ }^{\circ} \mathrm{C}\right)$ & Heating rate $\left({ }^{\circ} \mathrm{C} \min ^{-1}\right)$ & Mass (g) & Length $(\mathrm{cm})$ & Strain source & Reference \\
\hline 7.4 & $23.7 \pm 0.7$ & $0.3 \pm 0.03$ & $30 \pm 2$ & & British Columbia & (Zhang et al., 2018) \\
\hline 7.4 & $24.8 \pm 0.5$ & $0.3 \pm 0.03$ & $18 \pm 2$ & & British Columbia & (Zhang et al., 2018) \\
\hline 7.4 & $26.6 \pm 0.2$ & $0.3 \pm 0.03$ & $24 \pm 2$ & & British Columbia & (Zhang et al., 2018) \\
\hline 8 & $26.9 \pm 0.12$ & 0.1 & & $11.0-18.0$ & Washington & (Dale Becker \& Wolford, 1980) \\
\hline 9.8 & $27.9 \pm 0.05$ & 0.3 & & $15.3 \pm 0.25$ & Pennsylvania & (Carline \& Machung, 2001) \\
\hline 10 & $28.5 \pm 0.28$ & 0.02 & & $15.0-20.0$ & Arizona & (Lee \& Rinne, 1980) \\
\hline 10 & $28.0 \pm 0.12$ & 0.3 & $\sim 15.0$ & $\sim 10.0$ & Missouri & (Currie et al., 1998) \\
\hline 10 & $27.7 \pm 0.08$ & 0.3 & $12.9 \pm 0.6$ & & California & (Myrick \& Cech, 2000) \\
\hline 10 & $25.3 \pm 0.25$ & 0.03 & $1175.0 \pm 42.0$ & $41.1 \pm 0.4$ & Newfoundland & (Motyka et al., 2017) \\
\hline 10 & $26.3 \pm 0.3$ & $0.08 / 0.05$ & $487 \pm 34$ & $33.2 \pm 0.6$ & Alingsås Sweden & (Ekström et al., 2014) \\
\hline 19 & $25.9 \pm 0.2$ & 0.05 & $683 \pm 136$ & & Alingsås Sweden & (Ekström et al., 2014) \\
\hline 11 & $\sim 27.5$ & 0.3 & $8.0 \pm 1.6$ & & California & (Myrick \& Cech, 2005) \\
\hline $12^{\mathrm{a}}$ & $28.73 \pm 0.08$ & 0.3 & $2.4 \pm 0.05$ & & Blackwater & (Scott et al., 2015) \\
\hline $12^{\mathrm{a}}$ & $29.14 \pm 0.09$ & 0.3 & $2.4 \pm 0.05$ & & Tzenzaicut & (Scott et al., 2015) \\
\hline $12^{\mathrm{a}}$ & $29.11 \pm 0.09$ & 0.3 & $2.4 \pm 0.05$ & & Pennask & (Scott et al., 2015) \\
\hline 13 & $27.9 \pm 0.14$ & 0.33 & & $21.8 \pm 0.4$ & Ontario & (LeBlanc et al., 2011) \\
\hline 14 & $28.5 \pm 0.11$ & 0.3 & $13.8 \pm 0.8$ & & California & (Myrick \& Cech, 2000) \\
\hline 14 & $29.4 \pm 0.1$ & $0.033^{\mathrm{b}}$ & $41.0-140.0$ & & Oregon & (Rodnick et al., 2004) \\
\hline 15 & $29.4 \pm 0.08$ & 0.3 & & & & (Strange et al., 1993) \\
\hline 15 & $29.1 \pm 0.09$ & 0.3 & $\sim 15.0$ & $\sim 10.0$ & Missouri & (Currie et al., 1998) \\
\hline 15 & $27.7 \pm 0.03$ & $0.0014^{c}$ & $89.9 \pm 5.4$ & $11.9-0.3$ & North Carolina & Galbreath et al., 2006 \\
\hline 15 & $\sim 28.4$ & 0.3 & $9.3 \pm 2.0$ & & California & (Myrick \& Cech, 2005) \\
\hline 15 & $\sim 29.65$ & $0.083^{d}$ & & & Miyazaki, Japan & (Ineno et al., 2005) \\
\hline 15 & $29.0 \pm 0.02$ & $0.3 / 0.1$ & $30.2 \pm 0.3$ & $13.0 \pm 0.4$ & Western Australia & (Chen et al., 2015) \\
\hline 15 & $29.1 \pm 0.19$ & 0.083 & $10.8 \pm 2.03$ & $8.7 \pm 1.9$ & Nikko & (Ineno et al., 2018) \\
\hline 15 & $29.2 \pm 0.17$ & 0.083 & $8.8 \pm 1.5$ & $8.6 \pm 0.48$ & Aomori & (Ineno et al., 2018) \\
\hline 15 & $29.8 \pm 0.08$ & $0.3 / 0.1$ & $2.5 \pm 0.2$ & & Little Jacks Creek & (Chen et al., 2018a) \\
\hline 15 & $28.8 \pm 0.08$ & $0.3 / 0.1$ & $2.5 \pm 0.2$ & & Fawn Creek & (Chen et al., 2018a) \\
\hline 15 & $29.3 \pm 0.07$ & $0.3 / 0.1$ & $2.5 \pm 0.2$ & & Keithley Creek & (Chen et al., 2018a) \\
\hline 16 & $29.0 \pm 0.2$ & 0.3 & $4.6 \pm 0.5$ & $8.2 \pm 0.2$ & Turku, Finland & (Anttila et al., 2017) \\
\hline 18 & $\sim 31.2$ & 0.3 & & $4.1-20$ & Arizona & (Recsetar et al., 2012) \\
\hline 19 & $\sim 29.6$ & 0.3 & $14.3 \pm 2.9$ & & California & (Myrick \& Cech, 2005) \\
\hline
\end{tabular}

Note: This updates the content of table 5 in Chen et al., 2015.

${ }^{a}$ Fish held at $10-12^{\circ} \mathrm{C}$.

${ }^{\text {b }}$ Temperature was increased at $2^{\circ} \mathrm{C}$ per hour.

'Temperature was increased at $2^{\circ} \mathrm{C}$ per day.

'Temperature was increased at $5^{\circ} \mathrm{C}$ per hour. " " indicates an estimated or calculated mean by original author. Values separated by “-” represent the range of the traits. Other values were given as mean \pm S.E.M.

over their existing thermal range. The fact that fishes show a finite capacity (a ceiling) for their plasticity in upper thermal tolerance may be a major factor in their sensitivity to global warming, including extreme seasonal events (Gunderson \& Stillman, 2015). This is argued to be especially true for stenothermal tropical species that already live at temperatures close to their $\mathrm{CT}_{\max }$ (Comte \& Olden, 2017; Gunderson \& Stillman, 2015). For temperate species with a broad latitudinal range and panmictic population structure, safety margins are wider but are expected to be lower for populations at the warm edge of their distribution (Bennett et al., 2019). Developmental plasticity in $\mathrm{CT}_{\max }$ has been shown in the zebrafish Danio rerio (Hamilton 1822), a tropical eurytherm (Schaefer \& Ryan, 2006) and sockeye salmon O. nerka (Walbaum 1792), a temperate stenotherm (Chen et al., 2013). In both species, exposure of groups of fish to warmer temperatures during embryonic development increased their $\mathrm{CT}_{\max }$ later in life.

TPCs explicitly measure intraspecific plasticity, how performance varies at different exposure temperatures, within a fish species or across its populations (Currie \& Schulte, 2014; Schulte et al., 2011). 


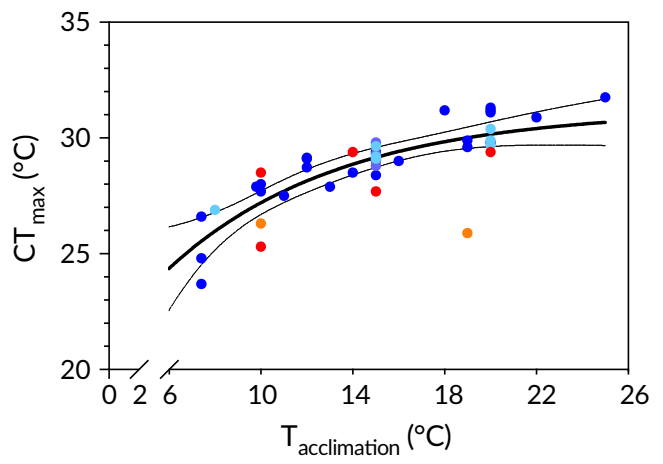

FIGURE 3 Model of the hyperbolic relationship between critical thermal maximum $\left(\mathrm{CT}_{\max }\right)$ and acclimation temperature using various strains of Oncorhynchus mykiss Walbaum. $\mathrm{CT}_{\max }$ was fitted with a one-phase association equation $(y=16.0+(31.2-16.0) *(1-\exp$ $\left.\left.\left[-0.13^{*} x\right]\right) R^{2}=0.66, P=0.0003\right)$. Information on fish size and origins are presented in Table 1. Each point represents a mean value. Colours denote different warming rates. Shaded area represents the $95 \%$ confidence interval. (o) $0.001-0.03^{\circ} \mathrm{C} \mathrm{min}^{-1}$, (০) $0.05-0.065^{\circ} \mathrm{C} \mathrm{min}^{-1}$, (॰) $0.083-0.1^{\circ} \mathrm{C} \mathrm{min}^{-1}$, (॰) $0.2^{\circ} \mathrm{C} \mathrm{min}^{-1}$ and (॰) $0.3^{\circ} \mathrm{C} \mathrm{min}^{-1}$

Effects of temperature on AAS differ among fish species (Lefevre, 2016), indicating much underlying variation in plastic responses to temperature, which remains to be understood. The time of exposure to temperatures also varies widely among studies, from acute (hours) to long-term (months to years), further hindering any analysis of patterns in plasticity of performance (Lefevre, 2016; Schulte et al., 2011). If acutely exposed to a range of temperatures, immediate impacts on fish performance represent "passive" plasticity and will expose limitations in sustaining performance (e.g., AAS) at temperatures as they diverge from $T_{\text {opt }}$ (Eliason et al., 2011; Munday et al., 2017). Long-term acclimation to the temperatures is expected to provide adequate time for active plastic compensation of metabolic traits, presumably towards optimizing performance at the new temperature (Claireaux et al., 2006; Ferreira et al., 2014; Healy \& Schulte, 2012; Norin et al., 2014; Sandblom et al., 2014, 2016; Slesinger et al., 2019).

The capacity of fishes to engage active compensation of thermal effects on SMR and MMR and the resultant effects on AAS (Figure 2) have been investigated, in particular, by comparing the $\mathrm{Q}_{10}$ for the traits after acute and chronic exposure at common temperatures. This is typically for a single temperature, insufficient to generate a TPC but informative all the same. For example, when a temperate marine species, the shorthorn sculpin Myoxocephalus scorpius L. 1758, acclimated to $10^{\circ} \mathrm{C}$ was warmed to $16^{\circ} \mathrm{C}$, SMR rose with a $Q_{10}$ of 2.7 at 1 week, leading to a decline in AAS, but AAS was restored after 16 weeks by a progressive decline in SMR to achieve perfect thermal compensation and a $Q_{10}$ of 1 (Sandblom et al., 2014). In the tropical barramundi Lates calcalifer (Bloch 1790) acclimated to $29^{\circ} \mathrm{C}$, acute exposure to $38^{\circ} \mathrm{C}$ caused an increase in SMR, MMR and AAS; nonetheless, after 5 weeks acclimation at $38^{\circ} \mathrm{C}$, MMR and SMR had both declined such that AAS was now similar again to the fish at $29^{\circ} \mathrm{C}$ (Norin et al., 2014). In the temperate black sea bass Centropristis striata (L. 1758) acclimated to $22^{\circ} \mathrm{C}$, acute exposure to $30^{\circ} \mathrm{C}$ raised SMR and MMR but AAS remained constant, whereas, after 1 month at $30^{\circ} \mathrm{C}, \mathrm{SMR}$ had not changed but MMR and AAS had declined significantly (Slesinger et al., 2019). Sandblom et al. (2016) compared two populations of European perch Perca fluviatilis L. 1758 in the Baltic sea, one that lived in the sea itself (Baltic perch) and one that lived inside a man-made enclosure that had been warmed for 30 years by thermal effluent from a nuclear power station (Biotest Perch). When Baltic perch acclimated to $18^{\circ}$ were acutely exposed to $23^{\circ} \mathrm{C}$, both SMR and MMR rose and AAS did not change. In the Biotest perch at $23^{\circ} \mathrm{C}$, AAS was higher than the Baltic fish that had been acutely exposed but this was achieved by lowering SMR, with MMR being similar in the two populations. This respiratory response was mirrored in cardiac performance, in terms of resting and maximum cardiac output and the resultant cardiac scope (Sandblom et al., 2016). Collectively, these studies show a range of different thermal acclimation responses for AAS, over different time scales, with no generalized pattern.

Studies have investigated how a TPC for AAS, measured over a range of acute temperature exposures, varies with thermal acclimation (Ferreira et al., 2014; Healy \& Schulte, 2012; Poletto et al., 2017). Such studies are technically demanding but can reveal whether active plasticity in SMR, routine metabolic rate (RMR) and MMR (Figure 2), and resultant AAS with temperature acclimation, has the potential to change $T_{\text {opt }}$ and the form of a TPC, e.g., shifting $T_{\text {opt }}$ to higher temperatures with warm acclimation and potentially changing the breadth of performance. The most in-depth study is on the Atlantic killifish Fundulus heteroclitus (L. 1766), a small topminnow that inhabits intertidal salt marshes along the east coast of North America from the Gulf of the St. Lawrence River to northern Florida (Taylor, 1999). These habitats are very thermally dynamic over diurnal and seasonal time scales (Fangue et al., 2008; Schulte, 2007), and Atlantic killifish are extreme eurytherms that can withstand acute temperature changes greater than $30^{\circ} \mathrm{C}$ and can be acclimated to temperatures ranging from 2 to $35^{\circ} \mathrm{C}$ (Fangue et al., 2006). The species is a model for studies of intraspecific variation in thermal physiology of fishes because, over its biogeographic range, it is divided into two sub-species - a northern form, F. heteroclitus macrolepidotus (Walbaum 1792) and a southern form, F. heteroclitus heteroclitus (Morin \& Able, 1983), which differ in genetics, physiology, morphology and behaviour (Schulte, 2007, see below).

TPCs for AAS have been determined for both sub-species, comparing acute exposure and longer term acclimation (Healy \& Schulte, 2012). The most striking feature of the curves following acute temperature exposure is that they are extremely broad, with AAS maintained at a similar level from 10 to $30^{\circ} \mathrm{C}$. This insensitivity of AAS was not due to reduced thermal sensitivity of metabolic processes in general, because both RMR and MMR were thermally sensitive with $\mathrm{Q}_{10}$ between 2 and 3 . Thus, the insensitivity of AAS to an acute temperature change was a result of essentially parallel changes in RMR and MMR with temperature. A somewhat different picture emerged for TPCs determined for $F$. heteroclitus tested at their acclimation temperatures. These reveal a much narrower TPC for AAS, with a plateau 
for $T_{\text {opt }}$ between 25 and $30^{\circ} \mathrm{C}$ (Healy \& Schulte, 2012). The shape of the curve is strongly left-skewed, increasing gradually with temperature up to the $T_{\text {opt }}$ plateau, and then dropping sharply at temperatures above $30^{\circ} \mathrm{C}$ (Healy \& Schulte, 2012). The differences between the AAS TPCs of acutely exposed vs. acclimated killifish were largely because of changes in the RMR of warm-acclimated fish, with RMR at higher temperatures being depressed relative to that of acutely exposed animals (Healy \& Schulte, 2012).

Performance curves for AAS were also evaluated in another extreme eurytherm, the goldfish Carassius auratus L. 1756, acclimated to 12,20 or $28^{\circ} \mathrm{C}$ (Ferreira et al., 2014). In this species, peak AAS was rather insensitive to acclimation temperature and again was sustained by parallel increases in RMR and MMR, although both of these traits showed significant thermal compensation, with a $\mathrm{Q}_{10}$ between 1 and 1.5. The $T_{\mathrm{opt}}$ shifted to be centred on the acclimation temperature; a notable finding was that the AAS curve at $12^{\circ} \mathrm{C}$ was extremely broad and narrowed with progressive warm acclimation. Therefore, these two eurytherms maintained thermal performance across a wide range of temperatures by maintaining parallel thermal sensitivities of both routine and maximum aerobic performance up to the failure temperature, rather than having MMR constrained at a temperature lower than that for RMR.

Another study is for a stenothermal species, the chinook salmon Oncorhynchus tshawytscha (Walbaum 1792), that is found on the Pacific coast of North America from Alaska to southern California. A Californian population from the Mokelumne River Hatchery (Clements, CA, U.S.A.) can survive widely fluctuating rearing temperatures $\left(13-16,17-20\right.$ or $21-24^{\circ} \mathrm{C}$ ) and grow at temperatures up to $24^{\circ} \mathrm{C}$, albeit at significantly reduced rates (Marine \& Cech, 2004). Poletto et al. (2017) found that $\mathrm{O}_{2 \max }$ and AAS of this strain of Chinook salmon when acclimated to either 15 or $19^{\circ} \mathrm{C}$ was mostly insensitive to test temperatures from 12 to $23^{\circ} \mathrm{C}$, despite a marked increase in RMR with warming.

The only study that, to the best of the authors' knowledge, has investigated plasticity in the TPC for AAS during seasonal thermal acclimatization is on the temperate European seabass D. labrax L. 1756 (Claireaux et al., 2006). A cohort was measured for their SMR, $M M R$ and $A A S$ at seven temperatures over a seasonal thermal range from 7 to $30^{\circ} \mathrm{C}$, and SMR rose progressively with an average $Q_{10}$ of 1.76 and MMR with a Q10 of 1.69 such that thermal compensation was not perfect, but AAS nonetheless rose progressively across the natural thermal range (Claireaux et al., 2006).

Overall, although there is a strong evidence of reversible plasticity in TPCs in fishes, there are very few studies on very few species to draw firm conclusions about general patterns of plasticity in AAS with thermal acclimation. Nonetheless, one response that appears to be observed in multiple species is that when acclimated chronically, the capacity to raise MMR appears to be finite so that plastic adjustments to maintain AAS are often linked to a capacity offset $\mathrm{Q}_{10}$ effects on SMR (Ferreira et al., 2014; Healy \& Schulte, 2012; McArley et al., 2017; Norin et al., 2014; Sandblom et al., 2014, 2016; Slesinger et al., 2019). That is, the fishes recruit mechanisms to compensate for the thermodynamic effects of increased temperature on basal metabolic processes and their associated oxygen demand. Known thermal compensation mechanisms associated with warm acclimation in eurythermic fishes, which might enable them to offset thermodynamic effects on basal or routine metabolism, could include decreases in the amount (or density) of mitochondria and perhaps the efficiency of generating ATP (Johnston, 1982), of sarcoplasmic reticulum (Penney \& Goldspink, 1980), of capillaries (Egginton \& Sidell, 1989) and of red muscle (Johnston \& Lucking, 1978). Such compensations are thought to partially compensate for changes in cytoplasmic viscosity, diffusion rate and membrane fluidity (Egginton \& Sidell, 1989; Pörtner, 2001; Tansey \& Brock, 1972) and should result in $\mathrm{Q}_{10}$ values nearer to unity when comparisons are made between acclimation temperatures (Ferreira et al., 2014; Jayasundara \& Somero, 2013).

Le Roy et al. (2017) investigated developmental plasticity in thermal performance in guppies Poecilia reticulata Peters 1859 bred and raised at either 23 or $29^{\circ} \mathrm{C}$ (a thermal extreme in their natural range in Australia). After two generations of rearing at a common temperature of $26^{\circ} \mathrm{C}$, they were tested for their AAS at a range of acute temperature exposures $\left(18,26,32\right.$ and $\left.36^{\circ} \mathrm{C}\right)$. The temperature at which grandparents had been held had little effect on the TPC. Nonetheless, the same study reported transgenerational plasticity over three successive generations for the two temperature groups. Both temperature groups increased in AAS across the acute test temperatures, but guppies held at $29^{\circ} \mathrm{C}$ tended to have higher AAS at all test temperatures aside from $18^{\circ} \mathrm{C}$ and especially at $36^{\circ} \mathrm{C}$. There were complex differences between the sexes whereby in females such effects were strongest in the F2 generation and had tended to diminish by the F3, whereas in males they continued to become more pronounced across successive generations (Le Roy et al., 2017). In both sexes and at all temperatures, swimming performance was poor at $36^{\circ} \mathrm{C}$ despite a high AAS (Le Roy et al., 2017). Thus, this study shows complex potential effects of transgenerational plasticity and, although such studies are technically very difficult to perform, more research is required in this area (Donelson et al., 2018).

Reversible, developmental and transgenerational plasticity all contributes to intraspecific variation in tolerance of warming in fishes and has the potential to buffer species against the negative effects of climate warming. In essence, "buying time" by allowing a species to persist as the environment changes. This may enable long-term evolutionary responses by populations, if it protects population size and underlying genetic diversity in the face of initial warming (Crispo, 2008). By contrast, a buffering effect of plasticity can also hinder adaptation by shielding a population from natural selection. Thus, the question of whether intraspecific variation generated by plasticity will help or hinder long-term persistence of a species in the face of climate change remains far from settled (Fox et al., 2019).

\section{6 | INTRASPECIFIC VARIATION IN THERMAL TOLERANCE DUE TO HERITABLE GENETIC VARIATION WITHIN POPULATIONS}

$\mathrm{CT}_{\max }$ is a heritable trait (Doyle et al., 2011; Meffe et al., 1995; Perry et al., 2005) that shows familial variation in Atlantic salmon Salmo salar 
L. 1756 and Atlantic cod Gadus morhua L. 1756 grown under common garden conditions (Anttila et al., 2013; Gradil et al., 2016; Muñoz et al., 2014, 2015; Zanuzzo et al., 2019). Within individuals of a few species such as European sea bass, zebrafish or guppies $P$. reticulata Peters 1859, $\mathrm{CT}_{\max }$ is a repeatable trait over quite extended periods (Claireaux et al., 2013; Grinder et al., 2020; Mauduit et al., 2019), which is a prerequisite for it to be subject to selection (Killen et al., 2016a).

Given the evidence that $\mathrm{CT}_{\max }$ is temporally stable and heritable, there have been attempts to investigate whether variation in acute thermal tolerance is significant for fitness, by exposing fish to challenging conditions in mesocosms. In three studies with European sea bass, upper thermal tolerance (measured as TLOE) was compared to correlates of fitness (survival and growth) in populations of more than 100 individuals stocked into a set of semi-natural tidal ponds for a period of 6 months. Each pond sustained a natural food web with a carrying capacity for 2-3 kg of fish in the spring but much less in autumn, when productivity declined (Claireaux et al., 2013; Mauduit et al., 2016, 2019). The sea bass showed broad individual variation in thermal tolerance, with a nearly twofold difference in TLOE between the least and most tolerant fish. The relationship of thermal tolerance to individual fitness in the pond depended on the pattern of selection pressure. In years when selection pressure was weak (overall survival $>60 \%$ over the 6 months), there was no relationship between TLOE and survival or growth (Mauduit et al., 2016, 2019). On the contrary, in the year that was characterized by strong selective pressure (survival rate was halved to $\approx 30 \%$ ), individual TLOE was a predictor of survival (Claireaux et al., 2013). These field studies highlight the complexity with which individual variation in tolerance can impact ecological performance, and they illustrate that caution is required when interpreting the significance of tolerance in an evolutionary context. Quite clearly, further research is warranted.

A few studies have started to probe the genetic basis of heritable differences in $\mathrm{CT}_{\max }$. Several early studies using quantitative trait locus mapping revealed genomic regions associated with variation in $\mathrm{CT}_{\max }$ in a variety of salmonids including rainbow trout (Jackson et al., 1998; Perry et al., 2001, 2005), Arctic charr Salvelinus alpinus L. 1758 (Quinn et al., 2011; Somorjai et al., 2003) and cutthroat trout O. clarkii (Richardson 1836) (Robinson, 2010). More recently, in Atlantic killifish, multilocus association mapping showed that 47 single nucleotide polymorphisms (SNPs) could explain $43.4 \%$ of the withinpopulation variation in thermal variation in $\mathrm{CT}_{\max }$ (Healy et al., 2018). Several of the SNPs associated with $\mathrm{CT}_{\max }$ fall within genes coding for transmembrane ion channels, consistent with the suggestion that the temperature-dependent depression of electrical excitability may explain the impaired electrical excitability of ventricular cardiac myocytes (and potentially other excitable cells) at high temperature (Vornanen, 2016) and thus underlie variation in tolerance to acute warming. Similarly, one of the SNPs associated with variation in $\mathrm{CT}_{\max }$ falls within a gene encoding a ubiquitin E3 ligase, implicating variation in protein degradation and repair processes as potentially important in shaping intraspecific variation in thermal tolerance. In rainbow trout, association mapping identified 207 genomic regions that were strongly associated with either variation in maximum heart rate or rate-limiting temperatures among individuals, with the identification of candidate genes that fall within pathways associated with cardiac function, the neuroendocrine system and the stress response (Chen et al., 2018b). Taken together, these studies suggest that intraspecific variation in tolerance to warming in fishes has a strong genetic basis, but that this variation is polygenic - the result of variation at multiple interacting genes. Nothing is known about heritability of variation in TPCs for any trait and may never be, because of the technical challenge of measuring curves on the large numbers of individuals needed to estimate heritability of complex traits that are polygenic (Muñoz et al., 2014, 2015). Nonetheless, there is evidence for heritability of traits that may impact upon a TPC, e.g., AAS (Munday et al., 2017).

Therefore, there is heritable genetic variation in tolerance of warming within fish populations, a substrate upon which natural selection can act. Incorporating the potential evolutionary responses of populations to climate change will be critical for accurately predicting the responses of fish species to ongoing warming (Waldvogel et al., 2020).

\section{I INTRASPECIFIC VARIATION IN THERMAL TOLERANCE AMONG POPULATIONS: DETAILED CASE STUDIES}

In many cases where variation in thermal tolerance is observed among and within fish populations, the relative contributions of plasticity vs. adaptation are not known. Distinguishing between plastic and heritable variation requires common garden experiments or pedigree studies, which are technically challenging for fishes that typically have quite long life spans and that cannot be followed easily in their natural environment (e.g., Chen et al., 2015; Gradil et al., 2016; Le Roy et al., 2017). Nonetheless, when species exhibit structured variation in tolerance, namely persistent differences among individuals in space or time, these can be of ecological and evolutionary significance (Bennett et al., 2019; Moran et al., 2016). That is, when comparing among populations at specific sites, phenotypic variation in tolerance will reflect responses to local thermal regimes.

There is extensive evidence of variation among populations in tolerance to warming; evidence is strongest in species where populations have little gene flow, a prime example being semelparous salmonids (Eliason et al., 2011; Jensen et al., 2008). For widespread marine species with broadcast spawning and panmictic population structures, it has been shown at an oceanic scale (e.g., Bradbury et al., 2010). Here the authors of this study summarize the results from three study systems where extensive investigations provide particular insights into the extent and nature of among-population variation in tolerance to warming.

\section{1 | Atlantic killifish}

Substantial phenotypic and genetic variation exists among F. heteroclitus populations in salt marshes and estuaries over their 
range from the St Lawrence estuary south to Florida, with relatively little gene flow from one habitat to another, providing conditions that are likely to promote local adaptation (Crawford et al., 2020). At a larger scale, the two sub-species differ in multiple aspects of tolerance to warming, with the southern sub-species generally being more tolerant than the northern. For example, southern $F$. heteroclitus have greater $\mathrm{CT}_{\max }$ than do northern, and these differences are maintained across the entire range of temperatures to which the species can be acclimated (Fangue et al., 2006) even with relatively modest differences $\left(c\right.$. $2^{\circ} \mathrm{C}$ ). Southern $F$. heteroclitus also tolerate higher temperatures in long-term thermal exposures, with chronic thermal maxima estimated to be $36.4^{\circ} \mathrm{C}$ for northern and $38.2^{\circ} \mathrm{C}$ for southern.

As is the case for upper thermal limits, there are also differences between the sub-species in cold tolerance. Northern F. heteroclitus have lower $\mathrm{CT}_{\min }$ than do southern, although $\mathrm{CT}_{\min }$ converges at the freezing point of water in fish of both sub-species if they are acclimated to temperatures below $15^{\circ} \mathrm{C}$ (Fangue et al., 2006). This pattern suggests that there may be a trade-off between upper and lower thermal tolerance in F. heteroclitus. Nonetheless, chronic thermal minima were not different between northern and southern killifish, with both sub-species surviving down to the freezing point of brackish water (Fangue et al., 2006).

Acute AAS curves are similar in both sub-species (Healy \& Schulte, 2012). In general, the height of the acute curve is greater in southern than in northern sub-species, and the upper thermal limit $\left(T_{\text {crit }}\right)$ for AAS of southern fish is modestly shifted to higher temperatures compared to those of northern. These results are generally consistent with trade-offs between upper and lower limits in this killifish but suggest that within this species there may not be trade-offs between the widths and heights of the TPC for AAS.

The shapes of the acclimated AAS curves are also similar between the sub-species (Healy \& Schulte, 2012), but in this case the height of the curve is greater in northern than in southern fish, suggesting a slightly greater capacity for thermal acclimation of scope in the northern sub-species. Nonetheless, these differences in acclimation capacity are minor and result from small differences between the subspecies in the effects of acclimation on both RMR and MMR.

These differences in tolerance to warming in adult $F$. heteroclitus are also evident during early development. Northern embryos are more cold-tolerant, and southern embryos are more warm-tolerant (DiMichele \& Westerman, 1997), with embryos of northern fish dying at temperatures of $30^{\circ} \mathrm{C}$, which embryos of southern $F$. heteroclitus can withstand. Thus, Atlantic killifish provide a clear example of differentiation between populations in tolerance to warming across multiple life stages.

\section{2 | Sockeye salmon}

O. nerka is an ideal species to examine local adaptation of thermal performance because it forms discrete genetic populations across a broad diversity of environments (Taylor, 1991). Sockeye populations return faithfully to their natal lake or stream to spawn, across their range from eastern Russia via Alaska to Oregon in the U.S.A. (Rand et al., 2012). Very broad diversity in life-history characteristics exists across populations (Burgner, 1991; Quinn, 2018; Wood, 1995). Eggs are deposited typically in the summer or fall in a gravel nest (redd); the fry usually spend 1-3 years in fresh water in either a lake or river habitat and then migrate out to the ocean for 1-3 years to feed and grow, before returning to their spawning grounds. Environmental characteristics vary enormously across the geographic range (e.g., temperature, elevation and river flow) and over the life history of the fish (e.g., redd to rearing lake/stream to ocean to return migration). Population differences in morphology, physiology, behaviour and lifehistory traits have been attributed to local adaptation (Crossin et al., 2004; Eliason et al., 2011; Fraser et al., 2011; Taylor, 1991).

Much of the research on intraspecific variation in O. nerka thermal tolerance has focused on the upriver adult spawning migration in the Fraser River watershed (British Columbia, Canada), a once-in-alifetime event. Warm river temperatures are associated with elevated mortality in migrating adults (Hinch \& Martins, 2011), raising conservation concerns for this iconic and economically important species. Aerobic scope is particularly relevant for adult salmon because fish must swim maximally to reach distant spawning grounds. Studies measuring a TPC for AAS found that $T_{\text {opt }}$ corresponds with the typical historical range of temperatures encountered during upriver migration in Fraser River O. nerka populations (Eliason et al., 2011, 2013; Farrell et al., 2008; Lee et al., 2003). The $T_{\text {opt }}$ varies from 14 to $17^{\circ} \mathrm{C}$ across populations, and $T_{\text {crit }}$ is estimated to be even more variable. Nonetheless, the $T_{\text {crit }}$ is essentially irrelevant for a migrating adult salmon because it is impossible for it to swim aerobically upstream for days at $T_{\text {crit. }}$ It is estimated that c. $90 \%$ of the maximum AAS at $T_{\text {opt }}$ is required to successfully migrate upstream. Tagging studies confirm that populations facing temperatures outside this range experience elevated mortality en-route (Eliason et al., 2011; Farrell et al., 2008; Martins et al., 2011). A biotelemetry study showed that when one population attempted an upstream migration of $<50 \mathrm{~km}$ when the river temperature was above the $T_{\text {opt }}$ for AAS, many fish did not reach their natal spawning area (Farrell et al., 2008). Furthermore, migration mortality rates differ across populations, and this can be attributed to differences in thermal tolerance (Hinch \& Martins, 2011). Tagging studies (Martins et al., 2011) and management estimates of escapement from fisheries (Hinch \& Martins, 2011) show that populations with a broader $T_{\text {opt }}$ window for AAS, such as the Chilko population (migration distance $642 \mathrm{~km}$ and elevation $1174 \mathrm{~m}$ ), have higher survival to the spawning grounds.

Fraser River populations such as Chilko and Harrison (migration distance $121 \mathrm{~km}$ and elevation $10 \mathrm{~m}$ ), which have a higher thermal tolerance compared to other co-migrating populations (Eliason et al., 2011, 2013), are helping to elucidate the mechanisms that underpin thermal tolerance. Focusing on the central importance of cardiac function for upper thermal tolerance, Chilko had a greater density of adrenaline-binding $\beta$-adrenoceptors on their ventricles compared to Nechako (migration distance $958 \mathrm{~km}$ and elevation $716 \mathrm{~m}$ ), a co-migrating population with a lower thermal tolerance. Chilko also had elevated cardiac sarco(endo)plasmic reticulum $\mathrm{Ca}^{2+}$ 
ATPase (SERCA) activity compared to three other populations. This suggests that the capacity to use adrenaline and cycle $\mathrm{Ca}^{2+}$ within the cardiomyocytes at high temperature may support cardiac performance and thus improve thermal tolerance. These ideas require further study, but like the Biotest perch (Sandblom et al., 2016) enhancements to cardiac performance can reflect a better thermal performance of AAS.

One study also examined $\mathrm{CT}_{\max }$ and its relation to cardiac $T_{\mathrm{AB}}$ across four populations of O. nerka fry (Chen et al., 2013). Eggs were collected from nine sockeye salmon spawning grounds, reared in a common garden environment at 10,14 and $16^{\circ} \mathrm{C}$, and the resultant fry were all held at ambient temperatures $\left(5-7^{\circ} \mathrm{C}\right)$. Across all populations, $\mathrm{CT}_{\max }$ was higher for fry reared at the lowest temperature (reflective of natal rearing temperatures) and decreased with warmer, stressful rearing temperatures. $\mathrm{CT}_{\max }$ also varied among populations, which strongly depended on body size. Interestingly, the $T_{\mathrm{AB}}$ was similar across four populations incubated at $10^{\circ} \mathrm{C}$ but differed across populations incubated at $14^{\circ} \mathrm{C}$ (a thermally stressful temperature). Chilko fry reared at $14^{\circ} \mathrm{C}$ had the lowest $T_{\mathrm{AB}}$, but the highest overall $f_{\mathrm{H}}$ across all temperatures. Chilko fry inhabit a glacial lake at high elevation and thus may be locally adapted to cooler temperatures at this life stage.

Thus, there is very strong evidence that thermal tolerance has a genetic component, and that variation in tolerance among sub-species or populations is linked to local adaptation, with $F$. heteroclitus and O. nerka providing detailed empirical studies of the physiological manifestations of such adaptation.

\section{3 | Rainbow trout}

Studies on rainbow trout provide ample evidence of variation in thermal tolerance in populations and strains across different sites. The rainbow trout is a model species for fish physiologists globally, and therefore its thermal and cardiorespiratory physiologies are very well studied. Generally regarded as a cold-water species within its range of Pacific coastal waters and tributary streams from the Kamchatka Peninsula to northern Mexico (Behnke, 2002), rainbow trout have been introduced onto all continents except Antarctica (Crawford et al., 2008), suggesting a tremendous physiological plasticity and perhaps adaptability. The inland strain of redband trout 0 . mykiss gairdneri inhabits desert streams where summer daytime highs can approach $30^{\circ} \mathrm{C}$ (Chen et al., 2018a). Three domesticated strains of O. mykiss raised and tested in common garden hatchery conditions exhibited differences in $\mathrm{CT}_{\max }$ (Zhang et al., 2018). The strain with the highest $\mathrm{CT}_{\max }$ also had the best cardiorespiratory performance (highest MMR and AAS). Importantly, the strain with superior $\mathrm{CT}_{\max }$ and high aerobic capacity also had a lower critical partial pressure for tolerance of hypoxia $\left(P_{\text {crit }}\right)$. This indicates a potential genetically based link between tolerance of warming and of hypoxia, which is another major stressor associated with global change (Zhang et al., 2018). Thus, there are marked differences in thermal tolerance among strains and populations that have a genetic basis, opening up interesting research perspectives and possibilities.
The $\mathrm{CT}_{\max }$ for $\mathrm{O}$. mykiss depends on acclimation temperature (Table 2), increasing from $c .27^{\circ} \mathrm{C}$ for animals acclimated to $8^{\circ} \mathrm{C}$ to almost $32^{\circ} \mathrm{C}$ for those acclimated to $25^{\circ} \mathrm{C}$ (Figure 3). Intraspecific variation in thermal tolerance is revealed by population (or strain) differences in $\mathrm{CT}_{\max }$. Similarly, intraspecific differences in thermal sensitivity of growth are evident in Californian O. mykiss, where the Mount Shasta strain acclimated to $22-25^{\circ} \mathrm{C}$ grew $18 \%$ faster than the Eagle Lake strain (Myrick \& Cech, 2000). An excellent example of thermal adaptation occurred when the $O$. mykiss irideus strain was introduced into the Pemberton Freshwater Hatchery Centre, Western Australia, about 50 years ago (Molony, 2001; Molony et al., 2004). A breeding population was maintained at the hatchery despite mass mortalities during high summer temperature events, an example of "hard selection" which resulted in the emergence of a warm-tolerant $\mathrm{H}$-strain (Molony et al., 2004) that had less genetic diversity (Ward et al., 2003) than its parental stock (the S-strain). When acclimated to $15^{\circ} \mathrm{C}$, the $\mathrm{H}$-strain has a $\mathrm{CT}_{\max }$ in excess of $29^{\circ} \mathrm{C}$ and can maintain $90 \%$ of peak AAS up to $20^{\circ} \mathrm{C}$ during acute warming, with peak AAS at $18^{\circ} \mathrm{C}$ (Chen et al., 2015). Investigating how the animals acclimate successfully to temperatures higher than the $15^{\circ} \mathrm{C}$ is an interesting topic for future study because the Pemberton Hatchery staff routinely feed their $\mathrm{H}$-strain at temperatures up to $23^{\circ} \mathrm{C}$, a temperature well beyond the U.S. Environmental Protection Agency recommendation of $18^{\circ} \mathrm{C}$ for the 7 day average for daily maxima when managing O. mykiss habitats in the Pacific Northwest (USEPA, 2003).

In contrast to the bell-shaped TPC for AAS for the Australian $\mathrm{H}$ strain, wild $O$. mykiss irideus tested riverside in a mobile laboratory after capturing from the Tuolumne River in central California, with an ambient habitat temperature of $14-24^{\circ} \mathrm{C}$, had an unusually flat TPC for AAS during acute warming (Figure 4; Verhille et al., 2016). Although peak AAS was at $21.2^{\circ} \mathrm{C}$, AAS varied slightly (<5\%) between 17.8 and $24.6^{\circ} \mathrm{C}$; factorial aerobic scope (FAS, namely MMR/SMR) decreased with test temperature in both of these heat-tolerant $O$. mykiss irideus populations because SMR increased more than MMR (Figure 4). Nonetheless, at $25^{\circ} \mathrm{C}$ the FAS of the Tuolumne River population (2.1) was slightly greater than that of the $\mathrm{H}$-strain (1.8; Chen et al., 2015).

Redband trout are an example of thermal adaptation to warm conditions, with geographically isolated populations that inhabit both desert (e.g., Little Jacks Creek) and montane (e.g., Keithley and Fawn Creeks) habitats in Idaho, U.S.A., where daily and seasonal temperature oscillations differ considerably (Chen et al., 2018b). There are clear indications that the desert population has adapted its physiology to tolerate the warmer temperatures of its habitat (Chen et al., 2018a, 2018b); they have a significantly higher $\mathrm{CT}_{\max }$ (by $1^{\circ} \mathrm{C}$ ) and a broader thermal window for AAS $\left(>3^{\circ} \mathrm{C}\right)$ than the montane populations (Figure 3). These phenotypic traits were associated with differential expression of genes involved in stress responses, metabolic activity and the neuroendocrine system. In addition, the desert population has a $20 \%$ higher maximum $f_{H}$ than the montane population (Chen et al., 2018b), which again opens up interesting perspectives to investigate the underlying genetic pathways for cardiac function.

With the exception of the growth study of Myrick and Cech (2000), the population comparisons of thermal performance and 


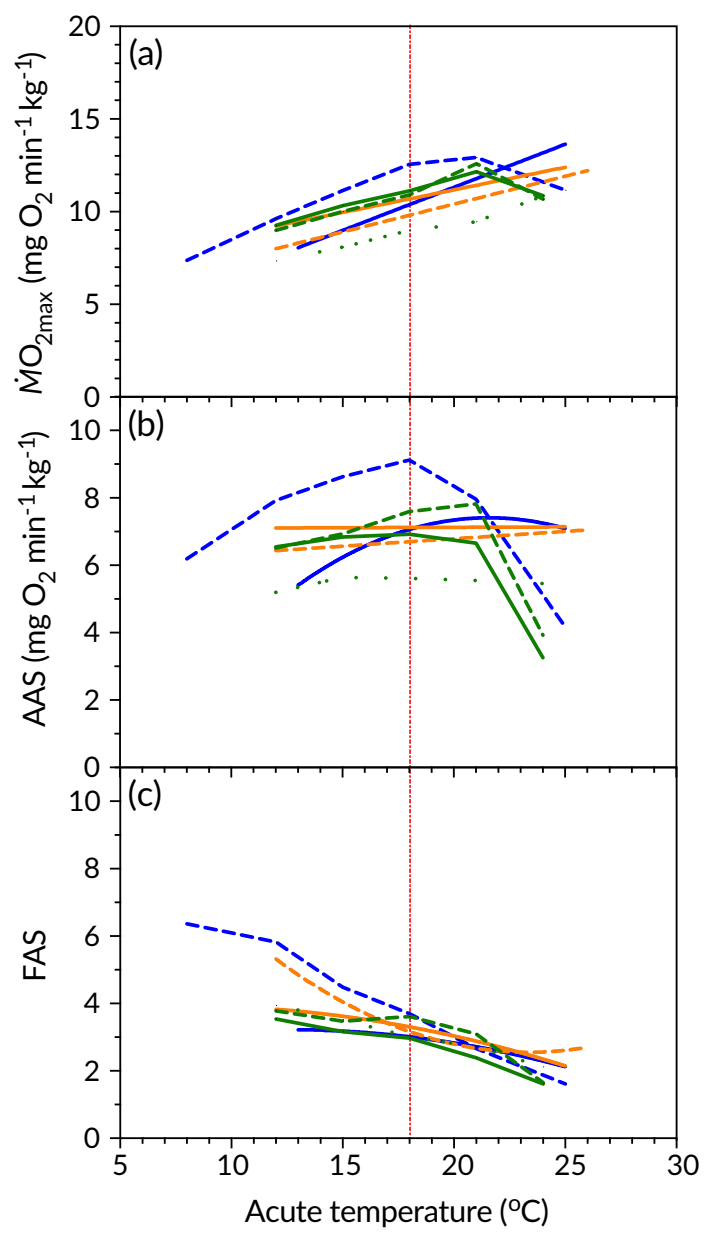

FIGURE 4 Maximum oxygen uptake ( $\left.\mathrm{O}_{2 \max } ; \mathrm{a}\right)$, absolute aerobic scope (AAS; b) and factorial aerobic scope (FAS; c) over a range of acute temperatures in various studies on Oncorhynchus spp. The studies had different settings, testing protocols and analytical techniques, as well as acclimation temperatures (indicated), but not all the differences in the curves can be attributed to these. A red vertical dash line marks $18^{\circ} \mathrm{C}$ as the 7 Day Average of the Daily Maxima criterion for management of rainbow trout habitat in the Pacific Northwest (U.S. Environmental Protection Agency, 2003). Rainbow trout Oncorhynchus mykiss, redband trout O. mykiss gairdneri and chinook salmon $O$. tshawytscha are in blue, green and orange, respectively. Patterns of lines differentiate the study groups. As noted by Verhille et al. (2016), peak AAS at $15^{\circ} \mathrm{C}$ for the wild Tuolumne River O. mykiss $\left(5.1 \mathrm{mg} \mathrm{O}_{2} \mathrm{~kg}^{-0.95} \mathrm{~min}^{-1}\right.$ ) is at the high end of previous laboratory measurements of AAS (1.8-5.8 $\mathrm{mg} \mathrm{O}_{2}$ $\mathrm{kg}^{-0.95} \mathrm{~min}^{-1}$ ) for 0 . mykiss at $15^{\circ} \mathrm{C}$, but lower than peak AAS (c. $7.3 \mathrm{mg} \mathrm{O}_{2}$ per kg-0.95 $\mathrm{min}^{-1}$ ) at $20^{\circ} \mathrm{C}$ in Australian O. mykiss (Chen et al., 2015). Notably, AAS at $24^{\circ} \mathrm{C}$ for Tuolumne River O. mykiss is greater than other $O$. mykiss populations. Although peak AAS of the Australian O. mykiss population was $50 \%$ greater than for the other two O. mykiss populations, Tuolumne River O. mykiss had the broadest and highest thermal window (from 17.8 to $24.6^{\circ} \mathrm{C}$ ) among the group. (-) $13^{\circ} \mathrm{C}$ O. mykiss, Verhille et al., $2016,(--) 15^{\circ} \mathrm{C}$ O. mykiss, Chen et al., 2015, (-) $15^{\circ} \mathrm{C}$ Fawn O. mykiss gairdneri, Chen et al., 2018, (-- ) $15^{\circ} \mathrm{C}$ Keithley O. mykiss gairdneri, Chen et al., 2018,

(. ) $15^{\circ} \mathrm{C}$ Little Jacks O. mykiss gairdneri, Chen et al., 2018, (-)

$15^{\circ} \mathrm{C}$ O. tshawytscha, Poletto et al., 2017 and (--) $19^{\circ} \mathrm{C}$

O. tshawytscha, Poletto et al., 2017 cardiac tolerance have not considered the potential significance of temperature acclimation, which is so important for $\mathrm{CT}_{\max }$ (Table 2, Figure 2). The chinook salmon is closely related to O. mykiss, and plasticity in thermal performance of the Californian fall-run O. tshawytscha from the Mokelumne River Hatchery has been described earlier. The Tuolumne River rainbow trout showed a similar thermal insensitivity (Verhille et al., 2016) (Figure 3). Thus, Californian fall-run O. tshawytscha and possibly Tuolumne River O. mykiss may have a broad thermal range for peak AAS, but a limited capacity to acclimate to warm temperatures. Muñoz et al. (2015) reared O. tshawytscha at $10^{\circ} \mathrm{C}, 4^{\circ} \mathrm{C}$ higher than the present-day rearing at $6^{\circ} \mathrm{C}$, and measured $f_{\mathrm{H} \text { max }}$ finding that $T_{\mathrm{AB}}$ and the temperature of peak maximum $f_{\mathrm{H}}\left(T_{\text {peakfH }}\right)$ increased by $2^{\circ} \mathrm{C}$, whereas $T_{\text {arr }}$ was unchanged. Therefore, O. tshawytscha show standing phenotypic variation and perhaps also have underlying genetic variation for $T_{\mathrm{AB}}$ and $T_{\text {peakfH }}$, but not for $T_{\text {arr. }}$.

The wide geographic distribution of $O$. mykiss shows an impressive capacity for phenotypic plasticity of this species that can have genomic or physiological origins. Studies on the warm-adapted Australian rainbow trout and redband trout provide a perspective on how the selection pressure of warm temperature might shape traits of tolerance. The general pattern that emerges is that a TPC flattens at high temperatures to extend the thermal window and support sufficient scope for activity. This is underpinned by cardiac performance, with maximum $f_{\mathrm{H}}$ sustained at warm temperatures, thereby increasing $\mathrm{T}_{\mathrm{AB}}$. These cardiac responses may be mechanisms underlying the higher $\mathrm{CT}_{\max }$ of trout strains and populations living at warm temperatures.

\section{8 | BROAD-SCALE STRUCTURED VARIATION IN THERMAL TOLERANCE}

At a geographic scale, variation in thermal tolerance is expected to be structured by large-scale environmental gradients and may reflect both plastic responses and underlying genetic diversity (Bennett et al., 2019). A well-known example of large-scale structured variation in thermal tolerance is related to the latitudinal range of a species (Bennett et al., 2019; Comte \& Olden, 2017), as this defines the range of temperatures that individuals are exposed to annually and over evolutionary time (Payne et al., 2016). At temperate latitudes the thermal variability is higher than in the tropics and polar regions, such that tropical and polar species are typically considered to be stenothermal. Tropical species also live closer to their upper thermal limits (Comte \& Olden, 2017), such that there would be less thermal margin for standing variation in tolerance to persist in tropical latitudes. Therefore, an expectation might be that temperate species would have greater variation in $\mathrm{CT}_{\max }$ compared to tropical or polar counterparts. Nati et al. (2020) calculated intraspecific variation in $\mathrm{CT}_{\max }$ for 203 species ( $N=127$ fresh water, $N=76$ marine), based simply on the standard deviation of the mean. A phylogenetically informed analysis revealed that intraspecific variation in $\mathrm{CT}_{\max }$ was greater in temperate than in 
tropical species, whereas there were very little data on polar species to include them in the analysis. There was a very strong phylogenetic signal in thermal tolerance, at the level of the family. This may indicate, at least in part, that species in many families share a common thermal history over evolutionary time and therefore have a similar thermal physiology (Nati et al., 2020

). This is a fertile area for future research.

\section{9 | ECOLOGICAL AND EVOLUTIONARY SIGNIFICANCE OF INTRASPECIFIC VARIATION}

The broad arguments about the significance of plasticity and genetic diversity to species vulnerability to global change have been made many times earlier and are now accepted wisdom. Nonetheless, it is interesting to interpret the empirical data of thermal tolerance in the light of specific theories about the ecological and evolutionary significance of intraspecific variation, in particular, to focus on the proposed mechanisms by which the extent of such variation may influence vulnerability to environmental stressors (Mimura et al., 2017; Moran et al., 2016; Pacifici et al., 2015).

Among the various mechanisms by which intraspecific variation in thermal tolerance could influence the sensitivity of a species to the impacts of global warming, the portfolio effect may be of particular significance (Bolnick et al., 2011; Moran et al., 2016). It is named in analogy to sensitivity to fluctuations in stock markets, where having a broad portfolio reduces the likelihood of losing all your investments. Greater variation within and among populations can buffer negative effects of climactic stressors and reduce the overall risk of negative effects on stability of the species. This effect does not require that variation is heritable, just that structured variation exists (Bolnick et al., 2011; Moran et al., 2016). An oft-cited example is the Alaskan sockeye salmon fishery which depends on hundreds of discrete salmon runs. Asynchrony in timing among local populations and cohorts reduces annual variability in overall migratory returns more than two-fold compared to if the populations were all synchronous, thereby contributing to long-term sustainability (Schindler et al., 2010). For tolerance of warming, one example where a portfolio effect might contribute to differences in vulnerability is latitudinal structuring, with the greater variation in $\mathrm{CT}_{\max }$ in temperate species compared to tropical species (Nati et al., 2020).

The "sampling effect" is linked to the portfolio effect but is more specific, being where possessing a broad range of phenotypes (and genotypes) within a population increases the likelihood that one has a high tolerance (Bolnick et al., 2011; Moran et al., 2016; Pacifici et al., 2015). This would also be relevant to the changes in the extent of variation in $\mathrm{CT}_{\max }$ with latitude (Nati et al., 2020), but may also underlie the response to hard selection for heat tolerance in rainbow trout farmed in Australia (Chen et al., 2015). The theory of "increased degree" is where populations themselves may have rather narrow and restricted variation in thermal sensitivity but tolerance differs widely among them, so broadening the overall range of tolerance in the species as a whole (Bolnick et al., 2011; Moran et al., 2016). This concept might be applied to the Fraser river sockeye populations because their individual thermal ranges for optimal AAS are quite narrow compared to other species, but population differences in $T_{\text {opt }}$ exist (Eliason et al., 2011). By contrast, one potential negative effect of having low intraspecific variation, or restricted variation within each population, is the risk of a local extinction (Moran et al., 2016). Here, the Fraser river sockeye salmon is also a prime example (Eliason et al., 2011). It remains a challenge for physiologists to provide data in support of these various hypotheses.

The effects mentioned so far do not distinguish whether diversity is phenotypic or genetic. The other major concept that defines vulnerability of a species to global warming is its adaptability or evolvability, which obviously focuses on heritable genetic variation (Bolnick et al., 2011; Mimura et al., 2017; Pacifici et al., 2015). The concept is simple; having a large degree of heritable variation can provide genotypes for new selections in a changing environment and contribute to populations fitting into the new environment (Bolnick et al., 2011; Mimura et al., 2017; Pacifici et al., 2015). Very little is known about the relative adaptability of species although it would seem selfevident that highly eurythermal species with short generation times, such as Atlantic killifish, would be more adaptable than the more stenothermal and longer-lived salmonids. Ongoing innovations in molecular biology may allow the direct investigation of functional genetic variants responsible for adaptation (Mimura et al., 2017; Razgour et al., 2019). For example, genomic studies of local adaptations can reveal the extent of molecular genetic diversity and how it relates to tolerance phenotypes and to prevailing environmental conditions at sites across a species' range (Razgour et al., 2019).

Overall, the authors of this study are far from understanding how variation in heat tolerance within species can actually contribute to their relative vulnerability to warming, and whether this occurs by any of the mechanisms proposed earlier. Improvements in technologies for rapid phenotyping of fishes, coupled with advances in sequencing, may provide access to testing the theories.

\section{0 | CONCLUSIONS}

There are well-established methods to investigate and assess intraspecific variation in tolerance of warming in fishes that can define absolute tolerance boundaries and how temperature affects performance within these. Nonetheless, the knowledge base is limited, and therefore more research is required to establish patterns that hold across multiple species. The evidence that tolerance changes systematically with life stages, and possibly with size as fishes become mature, should definitely be explored further and considered in projections of the sensitivity of species to future warming challenges. Phenotypic plasticity can reduce sensitivity to thermal stress, but there is an evidence that upper thermal tolerance has a "ceiling" in fishes, both in terms of $\mathrm{CT}_{\max }$ and capacity to raise MMR when warmed. Effective plasticity in aerobic performance may involve maintaining broad thermal breadth in the short term and thermal compensation of basal metabolism by acclimation over the 
longer term. Having extensive heritable genetic variation is expected to improve the potential for adaptability; nonetheless, this remains to be demonstrated. Overall, the existing empirical data cannot yet provide any insights into specific mechanisms linking intraspecific variation to vulnerability, such as the portfolio effect or adaptability/evolvability.

Nonetheless, the fact that intraspecific variation in tolerance is such an important component of overall species vulnerability highlights the need for further research into this component of biodiversity. It is also a clear message that such intraspecific variation should be fostered, managed and conserved whenever possible (Mimura et al., 2017; Moran et al., 2016; Pacifici et al., 2015). Promising avenues to evaluate the ecological and evolutionary significance of intraspecific variation include genomics and modelling. Advances in sequencing are opening up means to infer a role for physiological adaptation to the environment by linking genome-wide scans to prevailing environmental conditions (Mimura et al., 2017; Razgour et al., 2019). There are also methods to incorporate individual variation in physiological tolerance into mechanistic niche models (Kearney \& Porter, 2009; Moran et al., 2016; Pacifici et al., 2015), although this has not yet been achieved for fishes.

\section{ACKNOWLEDGEMENTS}

The authors are grateful to Valentina di Santo for providing some of the data on $\mathrm{CT}_{\max }$ reported in Table 1. Y.Z. was supported by an Elizabeth R. Howland Fellowship and a George Weston Ltd. Doctoral Fellowship; E.J.E. by Hellman Fellows Fund; F.R.B. by a CAPES Doctoral bursary; J.J.H.N. by a Marie-Curie Personal fellowship, whereas P.M.S. and A.P.F. were supported by grants from the Natural Sciences and Engineering Research Council of Canada (NSERC), and A.P.F. holds a Canada Research Chair.

\section{ORCID}

David J. McKenzie (D) https://orcid.org/0000-0003-0961-9101

\section{REFERENCES}

Angilletta, M. (2009). Thermal adaptation: A theoretical and empirical synthesis. Oxford, England: Oxford University Press.

Anttila, K., Couturier, C. S., Øverli, Ø., Johnsen, A., Marthinsen, G., Nilsson, G. E., \& Farrell, A. P. (2014). Atlantic Salmon show capability for cardiac acclimation to warm temperatures. Nature Communications, $5,1-6$

Anttila, K., Dhillon, R. S., Boulding, E. G., Farrell, A. P., Glebe, B. D., Elliott, J. A. K., ... Schulte, P. M. (2013). Variation in temperature tolerance among families of Atlantic Salmon (Salmo salar) is associated with hypoxia tolerance, ventricle size and myoglobin level. Journal of Experimental Biology, 216, 1183-1190.

Anttila, K., Mauduit, F., Le Floch, S., Claireaux, G., \& Nikinmaa, M. (2017). Influence of crude oil exposure on cardiac function and thermal tolerance of juvenile rainbow trout and European Sea bass. Environmental Science and Pollution Research, 24, 19624-19634.

Atkinson, D. (1994). Temperature and organism size-A biological law for ectotherms? Advances in Ecological Research, 25, 1-58.

Atkinson, D., \& Sibly, R. M. (1997). Why are organisms usually bigger in colder environments? Making sense of a life history puzzle. Trends in Ecology and Evolution, 12, 235-239.

Audzijonyte, A., Barneche, D. R., Baudron, A. R., Belmaker, J., Clark, T. D., Marshall, C. T., ... van Rijn, I. (2019). Is oxygen limitation in warming waters a valid mechanism to explain decreased body sizes in aquatic ectotherms? Global Ecology and Biogeography, 28, 64-77.

Audzijonyte, A., Richards, S. A., Stuart-Smith, R. D., Pecl, G., Edgar, G. J., Barrett, N. S., ... Blanchard, J. L. (2020). Fish body sizes change with temperature but not all species shrink with warming. Nature Ecology and Evolution, 1, 1-6.

Baudron, A. R., Needle, C. L., Rijnsdorp, A. D., \& Tara Marshall, C. (2014). Warming temperatures and smaller body sizes: Synchronous changes in growth of North Sea fishes. Global Change Biology, 20, 1023-1031.

Behnke, R. J. (2002). Trout and Salmon of North America. New York, NY: Free Press.

Beitinger, T., \& Lutterschmidt, W. (2011). Temperature| measures of thermal tolerance. In A. P. Farrell (Ed.), Encyclopedia of fish physiology: From genome to environment (pp. 1695-1702). San Diego, CA: Elsevier Ltd.

Bennett, S., Duarte, C. M., Marbà, N., \& Wernberg, T. (2019). Integrating within-species variation in thermal physiology into climate change ecology. Philosophical Transactions of the Royal Society B: Biological Sciences, 374, 20180550.

Björnsson, B., \& Tryggvadóttir, S. V. (1996). Effects of size on optimal temperature for growth and growth efficiency of immature Atlantic halibut (Hippoglossus hippoglossus L.). Aquaculture, 142, 33-42.

Blasco, F. R., Esbaugh, A. J., Killen, S., Rantin, F. T., Taylor, E. W., \& McKenzie, D. J. (2020b). Using aerobic exercise to evaluate sub-lethal tolerance of acute warming in fishes. Journal of Experimental Biology, 223, jeb218602.

Blasco, F. R., Taylor, E. W., Leite, C. A. C., Monteiro, D. A., Rantin, F. T., \& McKenzie, D. J. (2020a). Tolerance of an acute warming challenge declines with size in Nile tilapia: Evidence of a link to capacity for oxygen uptake. bioRxiv, 2020.12.03.409870.

Bolnick, D. I., Amarasekare, P., Araújo, M. S., Bürger, R., Levine, J. M., Novak, M., ... Vasseur, D. A. (2011). Why intraspecific trait variation matters in community ecology. Trends in Ecology and Evolution, 26, 183-192.

Bradbury, I. R., Hubert, S., Higgins, B., Borza, T., Bowman, S., Paterson, I. G., ... Bentzen, P. (2010). Parallel adaptive evolution of Atlantic cod on both sides of the Atlantic Ocean in response to temperature. Proceedings of the Royal Society B: Biological Sciences, 277, 3725-3734.

Brett, J. R. (1971). Energetic responses of Salmon to temperature. A study of some thermal relations in the physiology and freshwater ecology of sockeye Salmon ( Oncorhynchus nerka ). American Zoologist, 11, 99-113.

Burggren, W. W. (2019). Inadequacy of typical physiological experimental protocols for investigating consequences of stochastic weather events emerging from global warming. American Journal of Physiology, Regulatory, Integrative and Comparative Physiology, 316, R318-R322.

Burgner, R. L. (1991). Life history of sockeye Salmon. In C. Groot \& L. Margolis (Eds.), Pacific salmon life histories (pp. 1-117). Vancouver, BC: UBC Press.

Carline, R. F., \& Machung, J. F. (2001). Critical thermal maxima of wild and domestic strains of trout. Transactions of the American Fisheries Societyan Fisheries, 130, 1211-1216.

Casselman, M. T., Anttila, K., \& Farrell, A. P. (2012). Using maximum heart rate as a rapid screening tool to determine optimum temperature for aerobic scope in Pacific Salmon Oncorhynchus Spp. Journal of Fish Biology, 80, 358-377.

Chen, Z., Anttila, K., Wu, J., Whitney, C. K., Hinch, S. G., \& Farrell, A. P. (2013). Optimum and maximum temperatures of sockeye Salmon (Oncorhynchus nerka) populations hatched at different temperatures. Canadian Journal of Zoology, 91, 265-274.

Chen, Z., Farrell, A. P., Matala, A., Hoffman, N., \& Narum, S. R. (2018b). Physiological and genomic signatures of evolutionary thermal adaptation in Redband trout from extreme climates. Evolutionary Applications, 11, 1686-1699.

Chen, Z., Farrell, A. P., Matala, A., \& Narum, S. R. (2018a). Mechanisms of thermal adaptation and evolutionary potential of conspecific populations to changing environments. Molecular Ecology, 27, 659-674. 
Chen, Z., Snow, M., Lawrence, C., Church, A., Narum, S., Devlin, R., \& Farrell, A. (2015). Selection for upper thermal tolerance in rainbow trout (Oncorhynchus mykiss Walbaum). The Journal of Experimental Biology, 218, 803-812.

Cheung, W. W. L., Dunne, J., Sarmiento, J. L., \& Pauly, D. (2011). Integrating ecophysiology and plankton dynamics into projected maximum fisheries catch potential under climate change in the Northeast Atlantic. ICES Journal of Marine Science, 68, 1008-1018.

Claireaux, G., Couturier, C., \& Groison, A.-L. (2006). Effect of temperature on maximum swimming speed and cost of transport in juvenile European Sea bass (Dicentrarchus labrax). The Journal of Experimental Biology, 209, 3420-3428

Claireaux, G., \& Lefrançois, C. (2007). Linking environmental variability and fish performance: Integration through the concept of scope for activity. Philosophical transactions of the Royal Society of London. Series B, Biological sciences, 362, 2031-2041.

Claireaux, G., Théron, M., Prineau, M., Dussauze, M., Merlin, F. X., \& Le Floch, S. (2013). Effects of oil exposure and dispersant use upon environmental adaptation performance and fitness in the European Sea bass, Dicentrarchus labrax. Aquatic Toxicology, 130-131, 160-170.

Clark, T. D., Roche, D. G., Binning, S. A., Speers-Roesch, B., \& Sundin, J. (2017). Maximum thermal limits of coral reef damselfishes are size dependent and resilient to near-Future Ocean acidification. Journal of Experimental Biology, 220, 3519-3526.

Clark, T. D., Sandblom, E., \& Jutfelt, F. (2013). Aerobic scope measurements of fishes in an era of climate change: Respirometry, relevance and recommendations. Journal of Experimental Biology, 216, 2771-2782

Collins, M., Sutherland, M., Bouwer, L., Cheong, S.-M., Frölicher, T., Jacot Des Combes, H., ... Tibig, L.. (2019). Extremes, Abrupt Changes and Managing Risk. In: H.-O. Pörtner, D.C. Roberts, V. Masson-Delmotte, P. Zhai, M. Tignor, E. Poloczanska, K. Mintenbeck, A. Alegría, M. Nicolai, A. Okem, J. Petzold, B. Rama, N.M. Weyer (eds.). IPCC Special Report on the Ocean and Cryosphere in a Changing Climate. Retrieved from: https://www.ipcc.ch/srocc/cite-report

Comte, L., \& Olden, J. D. (2017). Climatic vulnerability of the World's freshwater and Marine fishes. Nature Climate Change, 7, 718-722.

Cossins, A. R., \& Bowler, K. (1987). Temperature biology of animals. London, England: Chapman and Hall.

Crawford, D. L., Schulte, P. M., Whitehead, A., \& Oleksiak, M. F. (2020). Evolutionary physiology and genomics in the highly adaptable killifish (Fundulus heteroclitus). Comprehensive Physiology, 10, 637-671.

Crawford, S. S., Andrew, A. E., \& Muir, M. (2008). Global introductions of Salmon and Trout in the genus Oncorhynchus: 1870-2007. Reviews in Fish Biology and Fisheries, 18, 313-344.

Crispo, E. (2008). Modifying effects of phenotypic plasticity on interactions among natural selection, adaptation and gene flow. Journal of Evolutionary Biology, 21, 1460-1469.

Crossin, G. T., Hinch, S. G., Farrell, A. P., Higgs, D. A., Lotto, A. G., Oakes, J. D., \& Healey, M. C. (2004). Energetics and morphology of sockeye Salmon: Effects of upriver migratory distance and elevation. Journal of Fish Biology, 65, 788-810.

Currie, R. J., Bennett, W. A., \& Beitinger, T. L. (1998). Critical thermal minima and maxima of three freshwater game-fish species acclimated to constant temperatures. Environmental Biology of Fishes, 51, 187-200.

Currie, S., \& Schulte, P. M. (2014). Thermal stress. In D. H. Evans, J. Claiborne, \& S. Currie (Eds.), The physiology of fishes 4th edn (pp. 257-279). Boca Raton, FL: CRC Press.

Dahlke, F. T., Wohlrab, S., Butzin, M., \& Pörtner, H.-O. (2020). Thermal bottlenecks in the life cycle define climate vulnerability of fish. Science, 369, 65-70.

Dale Becker, C., \& Wolford, M. G. (1980). Thermal resistance of juvenile salmonids sublethally exposed to nickel, determined by the critical thermal maximum method. Environmental Pollution. Series A, Ecological and Biological, 21, 181-189.
Daufresne, M., Lengfellner, K., \& Sommer, U. (2009). Global warming benefits the small in aquatic ecosystems. Proceedings of the National Academy of Sciences of the United States of America, 106, 12788-12793.

Deutsch, C., Ferrel, A., Seibel, B., Portner, H. O., \& Huey, R. B. (2015). Climate change tightens a metabolic constraint on Marine habitats. Science, 348, 1132-1136.

Di Santo, V., \& Lobel, P. S. (2017). Body size and thermal tolerance in tropical gobies. Journal of Experimental Marine Biology and Ecology, 487, 11-17.

DiMichele, L., \& Westerman, M. E. (1997). Geographic variation in development rate between populations of the teleost Fundulus heteroclitus. Marine Biology, 128, 1-7.

Donelson, J. M., Salinas, S., Munday, P. L., \& Shama, L. N. S. (2018). Transgenerational plasticity and climate change experiments: Where do we go from here? Global Change Biology, 24, 13-34.

Doyle, C. M., Leberg, P. L., \& Klerks, P. L. (2011). Heritability of heat tolerance in a small Livebearing fish, Heterandria Formosa. Ecotoxicology, 20, 535-542.

Drost, H. E., Fisher, J., Randall, F., Kent, D., Carmack, E. C., \& Farrell, A. P. (2016). Upper thermal limits of the hearts of Arctic cod Boreogadus saida: Adults compared with larvae. Journal of Fish Biology, 88, 718-726.

Egginton, S., \& Sidell, B. D. (1989). Thermal acclimation induces adaptive changes in subcellular structure of fish skeletal muscle. American Journal of Physiology - Regulatory Integrative and Comparative Physiology, 256, R1-R9.

Ekström, A., Jutfelt, F., \& Sandblom, E. (2014). Effects of autonomic blockade on acute thermal tolerance and cardioventilatory performance in rainbow trout, Oncorhynchus mykiss. Journal of Thermal Biology, 44, 47-54.

Eliason, E. J., \& Anttila, K. (2017). Temperature and the cardiovascular system. In A. K. Gamperl, T. E. Gillis, A. P. Farrell, \& C. J. Brauner (Eds.), Fish physiology (Vol. 36B, pp. 235-297). San Diego, CA: Elsevier Inc.

Eliason, E. J., Clark, T. D., Hague, M. J., Hanson, L. M., Gallagher, Z. S. Jeffries, K. M., ... Farrell, A. P. (2011). Differences in thermal tolerance among sockeye Salmon populations. Science (New York, N.Y.), 332 109-112.

Eliason, E. J., Wilson, S. M., Farrell, A. P., Cooke, S. J., \& Hinch, S. G. (2013). Low cardiac and aerobic scope in a coastal population of sockeye Salmon Oncorhynchus nerka with a short upriver migration. Journal of Fish Biology, 82, 2104-2112.

Fangue, N. A., Hofmeister, M., \& Schulte, P. M. (2006). Intraspecific variation in thermal tolerance and heat shock protein gene expression in common killifish, Fundulus heteroclitus. Journal of Experimental Biology, 209, 2859-2872.

Fangue, N. A., Mandic, M., Richards, J. G., \& Schulte, P. M. (2008). Swimming performance and energetics as a function of temperature in killifish Fundulus heteroclitus. Physiological and Biochemical Zoology, 81 389-401.

Farrell, A. P. (2009). Environment, antecedents and climate change: Lessons from the study of temperature physiology and river migration of salmonids. Journal of Experimental Biology, 212, 3771-3780.

Farrell, A. P. (2016). Pragmatic perspective on aerobic scope: Peaking, plummeting, Pejus and apportioning. Journal of Fish Biology, 88, 322-343.

Farrell, A. P., Hinch, S. G., Cooke, S. J., Patterson, D. A., Crossin, G. T., Lapointe, M., \& Mathes, M. T. (2008). Pacific Salmon in hot water: Applying aerobic scope models and biotelemetry to predict the success of spawning migrations. Physiological and Biochemical Zoology, 81, 697-708.

Ferreira, E. O., Anttila, K., \& Farrell, A. P. (2014). Thermal optima and tolerance in the Eurythermic goldfish (Carassius auratus): Relationships between whole-animal aerobic capacity and maximum heart rate. Physiological and Biochemical Zoology, 87, 599-611. 
Flynn, E. E., \& Todgham, A. E. (2018). Thermal windows and metabolic performance curves in a developing Antarctic fish. Journal of Comparative Physiology B: Biochemical, Systemic, and Environmental Physiology, 188, 271-282.

Fox, R. J., Donelson, J. M., Schunter, C., Ravasi, T., \& Gaitán-Espitia, J. D. (2019). Beyond buying time: The role of plasticity in phenotypic adaptation to rapid environmental change. Philosophical Transactions of the Royal Society B: Biological Sciences, 374, 20180174.

Fraser, D. J., Weir, L. K., Bernatchez, L., Hansen, M. M., \& Taylor, E. B. (2011). Extent and scale of local adaptation in salmonid fishes: Review and meta-analysis. Heredity, 106, 404-420.

Frölicher, T. L., \& Laufkötter, C. (2018). Emerging risks from Marine heat waves. Nature Communications, 9, 2015-2018.

Fry, F. E. J. (1947). The effects of the environment on animal activity. University of Toronto Studies: Biological Series, 55, 1-62.

Fry, F. E. J. (1957). The aquatic respiration of fish. In M. E. Brown (Ed.), The physiology of fishes (Vol. 1, pp. 1-63). New York, NY: Academic Press.

Fry, F. E. J. (1971). The effect of environmental factors on the physiology of fish. In W. S. Hoar \& D. J. Randall (Eds.), Fish physiology (Vol. 1, pp. 1-98). New York, NY: Academic Press.

Galbreath, P. F., Adams, N. D., Sherrill, L. W., \& Martin, T. H. (2006). Thermal tolerance of diploid versus triploid rainbow trout and brook trout assessed by time to chronic lethal maximum. Environmental Biology of Fishes, 75, 183-193.

Glazier, D. S. (2020). Activity alters how temperature influences intraspecific metabolic scaling: Testing the metabolic-level boundaries hypothesis. Journal of Comparative Physiology B: Biochemical, Systemic, and Environmental Physiology, 190, 445-454.

Gradil, K. J., Garner, S. R., Wilson, C. C., Farrell, A. P., \& Neff, B. D. (2016). Relationship between cardiac performance and environment across populations of Atlantic Salmon (Salmo salar): A common garden experiment implicates local adaptation. Evolutionary Ecology, 30, 877-886.

Gräns, A., Jutfelt, F., Sandblom, E., Jönsson, E., Wiklander, K., Seth, H., ... Axelsson, M. (2014). Aerobic scope fails to explain the detrimental effects on growth resulting from warming and elevated $\mathrm{CO} 2$ in Atlantic halibut. The Journal of Experimental Biology, 217, 711-717.

Grinder, R. M., Bassar, R. D., \& Auer, S. K. (2020). Upper thermal limits are repeatable in Trinidadian guppies. Journal of Thermal Biology, 90, 102597.

Gunderson, A. R., \& Stillman, J. H. (2015). Plasticity in thermal tolerance has limited potential to buffer ectotherms from global warming. Proceedings of the Royal Society B: Biological Sciences, 282, 20150401.

Habary, A., Johansen, J. L., Nay, T. J., Steffensen, J. F., \& Rummer, J. L. (2017). Adapt, move or die - How will tropical coral reef fishes cope with ocean warming? Global Change Biology, 23, 566-577.

Healy, T. M., Brennan, R. S., Whitehead, A., \& Schulte, P. M. (2018). Tolerance traits related to climate change resilience are independent and polygenic. Global Change Biology, 24, 5348-5360.

Healy, T. M., \& Schulte, P. M. (2012). Thermal acclimation is not necessary to maintain a wide thermal breadth of aerobic scope in the common killifish (Fundulus heteroclitus). Physiological and Biochemical Zoology, 85, 107-119.

Hinch, S. G., \& Martins, E. G. (2011). A review of potential climate change effects on survival of fraser river sockeye salmon and an analysis of interannual trends in en route loss and pre-spawn mortality the cohen commission of inquiry into the decline of Sockeye Salmon in the Fraser River.

Hoefnagel, K. N., \& Verberk, W. C. E. P. (2015). Is the temperature-size rule mediated by oxygen in aquatic ectotherms? Journal of Thermal Biology, 54, 56-65.

Illing, B., Downie, A. T., Beghin, M., \& Rummer, J. L. (2020). Critical thermal maxima of early life stages of three tropical fishes: effects of rearing temperature and experimental heating rate. Journal of Thermal Biology, 90,102582

Ineno, T., Tamaki, K., Yamada, K., Kodama, R., Tsuchida, S., Tan, E., ... Watabe, S. (2018). Thermal tolerance of a thermally selected strain of rainbow trout Oncorhynchus mykiss and the pedigrees of its $\mathrm{F} 1$ and F2 generations indicated by their critical thermal maxima. Fisheries Science, 84, 671-679.

Ineno, T., Tsuchida, S., Kanda, M., \& Watabe, S. (2005). Thermal tolerance of a rainbow trout Oncorhynchus mykiss strain selected by hightemperature breeding. Fisheries Science, 71, 767-775.

IPCC. (2014). Climate change 2014: Synthesis report. Geneva, Switzerland: Intergovernmental Panel on Climate Change.

Jackson, T. R., Ferguson, M. M., Danzmann, R. G., Fishback, A. G., Ihssen, P. E., O'Connell, M., \& Crease, T. J. (1998). Identification of two QTL influencing upper temperature tolerance in three rainbow trout (Oncorhynchus mykiss) half-sib families. Heredity, 80, 143-151.

Jayasundara, N., \& Somero, G. N. (2013). Physiological plasticity of cardiorespiratory function in a Eurythermal Marine teleost, the Longjaw Mudsucker, Gillichthys mirabilis. Journal of Experimental Biology, 216, 2111-2121.

Jensen, L. F., Hansen, M. M., Pertoldi, C., Holdensgaard, G., Mensberg, K. L. D., \& Loeschcke, V. (2008). Local adaptation in Brown trout early life-history traits: Implications for climate change adaptability. Proceedings of the Royal Society B: Biological Sciences, 275, 2859-2868.

Johnston, I., \& Lucking, M. (1978). Temperature induced variation in the distribution of different types of muscle fibre in the goldfish (Carassius auratus). Journal of Comparative Physiology B, 124, 111-116.

Johnston, I. A. (1982). Capillarisation, oxygen diffusion distances and mitochondrial content of carp muscles following acclimation to summer and winter temperatures. Cell and Tissue Research, 222, 325-337.

Jutfelt, F., Norin, T., Ern, R., Overgaard, J., Wang, T., McKenzie, D. J., ... Clark, T. D. (2018). Oxygen- and capacity-limited thermal tolerance: Blurring ecology and physiology. The Journal of Experimental Biology, 221, jeb169615.

Kearney, M., \& Porter, W. (2009). Mechanistic niche modelling: Combining physiological and spatial data to predict Species' ranges. Ecology Letters, 12, 334-350.

Killen, S. S., Adriaenssens, B., Marras, S., Claireaux, G., \& Cooke, S. J. (2016a). Context dependency of trait repeatability and its relevance for management and conservation of fish populations. Conservation Physiology, 4, 1-19.

Killen, S. S., Glazier, D. S., Rezende, E. L., Clark, T. D., Atkinson, D., Willener, A. S. T., \& Halsey, L. G. (2016b). Ecological influences and morphological correlates of resting and maximal metabolic rates across teleost fish species. The American Naturalist, 187, 592-606.

Komoroske, L. M., Connon, R. E., Lindberg, J., Cheng, B. S., Castillo, G., Hasenbein, M., \& Fangue, N. A. (2014). Ontogeny influences sensitivity to climate change stressors in an endangered fish. Conservation Physiology, 2. https://doi.org/10.1093/conphys/cou008.

Le Roy, A., Loughland, I., \& Seebacher, F. (2017). Differential effects of developmental thermal plasticity across three generations of guppies (Poecilia reticulata): Canalization and anticipatory matching. Scientific Reports, 7, 1-12.

LeBlanc, S., Middleton, S., Gilmour, K. M., \& Currie, S. (2011). Chronic social stress impairs thermal tolerance in the rainbow trout (Oncorhynchus mykiss). Journal of Experimental Biology, 214, 1721-1731.

Lee, C. G., Farrell, A. P., Lotto, A., MacNutt, M. J., Hinch, S. G., \& Healey, M. C. (2003). The effect of temperature on swimming performance and oxygen consumption in adult sockeye (Oncorhynchus nerka) and Coho (O. kisutch) Salmon stocks. Journal of Experimental Biology, 206, 3239-3251.

Lee, R. M., \& Rinne, J. N. (1980). Critical thermal maxima of five trout species in the southwestern United States. Transactions of the American Fisheries Society, 109, 632-635.

Lefevre, S. (2016). Are global warming and ocean acidification conspiring against Marine ectotherms ? A meta-analysis of the respiratory effects of elevated temperature, high CO 2 and their interaction. Conservation Physiology, 4, 1-31. 
Lefevre, S., McKenzie, D. J., \& Nilsson, G. E. (2017). Models projecting the fate of fish populations under climate change need to be based on valid physiological mechanisms. Global Change Biology, 23, 3449-3459.

Leiva, F. P., Calosi, P., \& Verberk, W. C. E. P. (2019). Scaling of thermal tolerance with body mass and genome size in ectotherms: A comparison between water- and air-breathers. Philosophical Transactions of the Royal Society B: Biological Sciences, 374(1778), 20190035.

Little, A. G., Loughland, I., \& Seebacher, F. (2020). What do warming waters mean for fish physiology and fisheries? Journal of Fish Biology, 97, 328-340.

Lutterschmidt, W. I., \& Hutchison, V. H. (1997). The critical thermal maximum: History and critique. Canadian Journal of Zoology, 75, 1561-1574.

Marine, K. R., \& Cech, J. J. (2004). Effects of high water temperature on growth, Smoltification, and predator avoidance in juvenile Sacramento RiverChinook Salmon. North American Journal of Fisheries Management, 24, 198-210.

Marras, S., Cucco, A., Antognarelli, F., Azzurro, E., Milazzo, M., Bariche, M., ... Domenici, P. (2015). Predicting future thermal habitat suitability of competing native and invasive fish species: From metabolic scope to oceanographic modelling. Conservation Physiology, 3, cou059. https:// doi.org/10.1093/conphys/cou059.

Martins, E. G., Hinch, S. G., Patterson, D. A., Hague, M. J., Cooke, S. J., Miller, K. M., ... Farrell, A. P. (2011). Effects of river temperature and climate warming on stock-specific survival of adult migrating Fraser River sockeye Salmon (Oncorhynchus nerka). Global Change Biology, 17, 99-114.

Mauduit, F., Domenici, P., Farrell, A. P., Lacroix, C., Le Floch, S., Lemaire, P., ... Claireaux, G. (2016). Assessing chronic fish health: An application to a case of an acute exposure to chemically treated crude oil. Aquatic Toxicology, 178, 197-208.

Mauduit, F., Farrell, A. P., Domenici, P., Lacroix, C., Le Floch, S., Lemaire, P., ... Claireaux, G. (2019). Assessing the long-term effect of exposure to dispersant-treated oil on fish health using hypoxia tolerance and temperature susceptibility as ecologically relevant biomarkers. Environmental Toxicology and Chemistry, 38, 210-221.

McArley, T. J., Hickey, A. J. R., \& Herbert, N. A. (2017). Chronic warm exposure impairs growth performance and reduces thermal safety margins in the common Triplefin fish (Forsterygion lapillum). Journal of Experimental Biology, 220, 3527-3535.

McDonnell, L. H., Reemeyer, J. E., \& Chapman, L. J. (2019). Independent and interactive effects of long-term exposure to hypoxia and elevated water temperature on behavior and thermal tolerance of an equatorial cichlid. Physiological and Biochemical Zoology, 92, 253-265.

Meffe, G. K., Weeks, S. C., Mulvey, M., \& Kandl, K. L. (1995). Genetic differences in thermal tolerance of eastern mosquitofish (Gambusia holbrooki; Poeciliidae) from ambient and thermal ponds. Canadian Journal of Fisheries and Aquatic Sciences, 52, 2704-2711.

Messmer, V., Pratchett, M. S., Hoey, A. S., Tobin, A. J., Coker, D. J., Cooke, S. J., \& Clark, T. D. (2017). Global warming may disproportionately affect larger adults in a predatory coral reef fish. Global Change Biology, 23, 2230-2240.

Mimura, M., Yahara, T., Faith, D. P., Vázquez-Domínguez, E., Colautti, R. I., Araki, H., ... Hendry, A. P. (2017). Understanding and monitoring the consequences of human impacts on intraspecific variation. Evolutionary Applications, 10, 121-139.

Molony, B. W. (2001). Environmental requirements and tolerances of rainbow trout (Oncorhynchus mykiss) and Brown trout (Salmo trutta) with special reference to Western Australia: A review. Fisheries Research Report Western Australia, 130, 1-28.

Molony, B. W., Church, A. R., \& Maguire, G. B. (2004). A comparison of the heat tolerance and growth of a selected and non-selected line of rainbow trout, Oncorhynchus mykiss, in Western Australia. Aquaculture, 241, 655-665.

Moran, E. V., Hartig, F., \& Bell, D. M. (2016). Intraspecific trait variation across scales: Implications for understanding global change responses. Global Change Biology, 22, 137-150.
Morin, R. P., \& Able, K. W. (1983). Patterns of geographic variation in the egg morphology of the Fundulid fish, Fundulus heteroclitus. Copeia, 1983, 726.

Motyka, R., Norin, T., Petersen, L. H., Huggett, D. B., \& Gamperl, A. K. (2017). Long-term hypoxia exposure alters the cardiorespiratory physiology of steelhead trout (Oncorhynchus mykiss), but does not affect their upper thermal tolerance. Journal of Thermal Biology, 68, 149-161.

Moyano, M., Candebat, C., Ruhbaum, Y., Álvarez-Fernández, S. Claireaux, G., Zambonino-Infante, J. L., \& Peck, M. A. (2017). Effects of warming rate, acclimation temperature and ontogeny on the critical thermal maximum of temperate Marine fish larvae. PLoS One, 12, 1-23.

Munday, P. L., Donelson, J. M., \& Domingos, J. A. (2017). Potential for adaptation to climate change in a coral reef fish. Global Change Biology, 23, 307-317.

Muñoz, N. J., Anttila, K., Chen, Z., Heath, J. W., Farrell, A. P., \& Neff, B. D. (2014). Indirect genetic effects underlie oxygen-limited thermal tolerance within a coastal population of Chinook Salmon. Proceedings of the Royal Society B: Biological Sciences, 281, 20141082.

Muñoz, N. J., Farrell, A. P., Heath, J. W., \& Neff, B. D. (2015). Adaptive potential of a Pacific Salmon challenged by climate change. Nature Climate Change, 5, 163-166.

Myrick, C., \& Cech, J. (2005). Effects of temperature on the growth, food consumption, and thermal tolerance of Age-0 Nimbus-strain steelhead. North American Journal of Aquaculture, 67, 324-330.

Myrick, C. A., \& Cech, J. J. (2000). Temperature influences on California rainbow trout physiological performance. Fish Physiology and Biochemistry, 22, 245-254.

Nati, J. J. H., Svendsen, M. B. S., Marras, S., Killen, S. S., Steffensen, J. F., McKenzie, D. J., \& Domenici, P. (2020). Intraspecific variation in thermal tolerance differs between tropical and temperate fishes. bioRxiv 2020. https://doi.org/10.1101/2020.12.07.414318.

Norin, T., Malte, H., \& Clark, T. D. (2014). Aerobic scope does not predict the performance of a tropical Eurythermal fish at elevated temperatures. Journal of Experimental Biology, 217, 244-251.

Pacifici, M., Foden, W. B., Visconti, P., Watson, J. E. M., Butchart, S. H. M., Kovacs, K. M., ... Rondinini, C. (2015). Assessing species vulnerability to climate change. Nature Climate Change, 5, 215-225.

Payne, N., Smith, J., van der Meulen, D., Taylor, M., Watanabe, Y., Takahashi, A., ... Suthers, I. (2016). Temperature dependence of fish performance in the wild: Links with species biogeography and physiological thermal tolerance. Functional Ecology, 30, 903-912.

Penney, R. K., \& Goldspink, G. (1980). Temperature adaptation of sarcoplasmic reticulum of fish muscle. Journal of Thermal Biology, 5 , 63-68.

Perry, G. M. L., Danzmann, R. G., Ferguson, M. M., \& Gibson, J. P. (2001). Quantitative trait loci for upper thermal tolerance in outbred strains of rainbow trout (Oncorhynchus mykiss). Heredity, 86, 333-341.

Perry, G. M. L., Martyniuk, C. M., Ferguson, M. M., \& Danzmann, R. G. (2005). Genetic parameters for upper thermal tolerance and growthrelated traits in rainbow trout (Oncorhynchus mykiss). Aquaculture, 250 120-128.

Pinsky, M. L., Eikeset, A. M., McCauley, D. J., Payne, J. L., \& Sunday, J. M. (2019). Greater vulnerability to warming of Marine versus terrestrial ectotherms. Nature, 569, 108-111.

Poletto, J. B., Cocherell, D. E., Baird, S. E., Nguyen, T. X., CabreraStagno, V., Farrell, A. P., \& Fangue, N. A. (2017). Unusual aerobic performance at high temperatures in juvenile Chinook Salmon, Oncorhynchus tshawytscha. Conservation Physiology, 5, cow067.

Pörtner, H. O. (2001). Climate change and temperature-dependent biogeography: Oxygen limitation of thermal tolerance in animals. Naturwissenschaften, 88, 137-146.

Pörtner, H. O. (2010). Oxygen- and capacity-limitation of thermal tolerance: A matrix for integrating climate-related stressor effects in Marine ecosystems. Journal of Experimental Biology, 213, 881-893. 
Pörtner, H. O., Bock, C., \& Mark, F. C. (2017). Oxygen- \& capacity-limited thermal tolerance: Bridging ecology \& physiology. Journal of Experimental Biology, 1(2017), 2685-2696. https://doi.org/10.1242/jeb. 134585.

Pörtner, H. O., \& Knust, R. (2007). Climate change affects Marine fishes through the oxygen limitation of thermal tolerance. Science (New York, N.Y.), 315, 95-97.

Pörtner, H. O., \& Peck, M. A. (2010). Climate change effects on fishes and fisheries: Towards a cause-and-effect understanding. Journal of Fish Biology, 77, 1745-1779.

Pörtner, H. O., Schulte, P. M., Wood, C. M., \& Schiemer, F. (2010). Niche dimensions in fishes: An integrative view. Physiological and Biochemical Zoology, 83, 808-826.

Quinn, N. L., Mcgowan, C. R., Cooper, G. A., Koop, B. F., \& Davidson, W. S. (2011). Identification of genes associated with heat tolerance in Arctic Charr exposed to acute thermal stress. Physiological Genomics, 43, 685-696.

Quinn, T. P. (2018). The behavior and ecology of Pacific Salmon and Trout. Seattle, WA: University of Washington Press.

Rand, P. S., Goslin, M., Gross, M. R., Irvine, J. R., Augerot, X., McHugh, P. A., \& Bugaev, V. F. (2012). Global assessment of extinction risk to populations of sockeye Salmon Oncorhynchus nerka. PLoS One, 7, e34065.

Razgour, O., Forester, B., Taggart, J. B., Bekaert, M., Juste, J., Ibáñez, C., ... Manel, S. (2019). Considering adaptive genetic variation in climate change vulnerability assessment reduces species range loss projections. Proceedings of the National Academy of Sciences of the United States of America, 116, 10418-10423.

Recsetar, M. S., Zeigler, M. P., Ward, D. L., Bonar, S. A., \& Caldwell, C. A. (2012). Relationship between fish size and upper thermal tolerance. Transactions of the American Fisheries Society, 141, 1433-1438.

Righton, D., Andersen, K., Neat, F., Thorsteinsson, V., Steingrund, P., Svedäng, H., ... Metcalfe, J. (2010). Thermal niche of Atlantic cod Gadus morhua: Limits, tolerance and optima. Marine Ecology Progress Series, 420, 1-13.

Robinson, M. L. (2010). Physiological and genetic factors influencing thermal tolerance in the Lahontan cutthroat trout (Oncorhynchus clarkii henshawi). Reno, NV: University of Nevada.

Rodnick, K. J., Gamperl, A. K., Lizars, K. R., Bennett, M. T., Rausch, R. N., \& Keeley, E. R. (2004). Thermal tolerance and metabolic physiology among Redband trout populations in south-eastern Oregon. Journal of Fish Biology, 64, 310-335.

Rombough, P. J. (1988). Respiratory gas exchange, aerobic metabolism, and effects of hypoxia during early life. In D. J. Randall \& W. S. Hoar (Eds.), Fish physiology (Vol. XIA, pp. 59-161). New York, NY: Academic Press.

Roze, T., Christen, F., Amerand, A., \& Claireaux, G. (2013). Trade-off between thermal sensitivity, hypoxia tolerance and growth in fish. Journal of Thermal Biology, 38, 98-106.

Sandblom, E., Clark, T. D., Gräns, A., Ekström, A., Brijs, J., Sundström, L. F., ... Jutfelt, F. (2016). Physiological constraints to climate warming in fish follow principles of plastic floors and concrete ceilings. Nature Communications, 7, 1-8.

Sandblom, E., Gräns, A., Axelsson, M., \& Seth, H. (2014). Temperature acclimation rate of aerobic scope and feeding metabolism in fishes: Implications in a thermally extreme future. Proceedings of the Royal Society B: Biological Sciences, 281, 20141490.

Schaefer, J., \& Ryan, A. (2006). Developmental plasticity in the thermal tolerance of zebrafish Danio rerio. Journal of Fish Biology, 69, 722-734.

Schindler, D. E., Hilborn, R., Chasco, B., Boatright, C. P., Quinn, T. P., Rogers, L. A., \& Webster, M. S. (2010). Population diversity and the portfolio effect in an exploited species. Nature, 465, 609-612.

Schulte, P. M. (2007). Responses to environmental stressors in an estuarine fish: Interacting stressors and the impacts of local adaptation. Journal of Thermal Biology, 32, 152-161.
Schulte, P. M. (2011). Effects of temperature: An introduction. In A. P. Farrell (Ed.), Encyclopedia of fish physiology: From genome to environment (pp. 1688-1694). San Diego, CA: Elsevier Inc.

Schulte, P. M. (2015). The effects of temperature on aerobic metabolism: Towards a mechanistic understanding of the responses of ectotherms to a changing environment. The Journal of Experimental Biology, 218, 1856-1866.

Schulte, P. M., Healy, T. M., \& Fangue, N. A. (2011). Thermal performance curves, phenotypic plasticity, and the time scales of temperature exposure. Integrative and Comparative Biology, 51, 691-702.

Scott, M. A., Dhillon, R. S., Schulte, P. M., \& Richards, J. G. (2015). Physiology and performance of wild and domestic strains of diploid and triploid rainbow trout ( Oncorhynchus mykiss ) in response to environmental challenges. Canadian Journal of Fisheries and Aquatic Sciences, 72, 125-134.

Slesinger, E., Andres, A., Young, R., Seibel, B., Saba, V., Phelan, B., ... Saba, G. (2019). The effect of ocean warming on Black Sea bass (Centropristis striata) aerobic scope and hypoxia tolerance. PLoS One, 14, 1-22.

Somorjai, I. M. L., Danzmann, R. G., \& Ferguson, M. M. (2003). Distribution of temperature tolerance quantitative trait loci in Arctic Charr (Salvelinus alpinus) and inferred homologies in rainbow trout (Oncorhynchus mykiss). Genetics, 165, 1443-1456.

Spicer, J. I., \& Gaston, K. J. (2000). Physiological diversity: Ecological implications, Oxford: Blackwell Sciences Ltd.

Spinks, R. K., Munday, P. L., \& Donelson, J. M. (2019). Developmental effects of heatwave conditions on the early life stages of a coral reef fish. Journal of Experimental Biology, 222, jeb202713.

Stearns, S. C. (1989). The evolutionary significance of phenotypic plasticity - phenotypic sources of variation among organisms can be described by developmental switches and reaction norms. Bioscience, 39, 436-445.

Steinhausen, M. F., Sandblom, E., Eliason, E. J., Verhille, C., \& Farrell, A. P. (2008). The effect of acute temperature increases on the cardiorespiratory performance of resting and swimming sockeye Salmon (Oncorhynchus nerka). Journal of Experimental Biology, 211, 3915-3926.

Strange, J., Petrie, R. B., \& Cech, J. J. (1993). Slight stress does not lower critical thermal maximums in Hatcherry-reared rainbow trout. Folia Zoologica (Brno), 42, 251-256.

Sunday, J. M., Bates, A. E., \& Dulvy, N. K. (2011). Global analysis of thermal tolerance and latitude in ectotherms. Proceedings. Biological Sciences, 278, 1823-1830.

Tansey, M. R., \& Brock, T. D. (1972). The upper temperature limit for eukaryotic organisms. Proceedings of the National Academy of Sciences of the United States of America, 69, 2426-2428.

Taylor, E. B. (1991). A review of local adaptation in Salmonidae, with particular reference to Pacific and Atlantic Salmon. Aquaculture, 98, 185-207.

Taylor, M. H. (1999). A suite of adaptations for intertidal spawning. Integrative and Comparative Biology, 39, 313-320.

U.S. Environmental Protection Agency. (2003). EPA region 10 guidance for Pacific northwest state and tribal water quality standards, Seattle, WA: EPA 910-B-03-002. US EPA.

van Wijk, S. J., Taylor, M. I., Creer, S., Dreyer, C., Rodrigues, F. M., Ramnarine, I. W., ... Carvalho, G. R. (2013). Experimental harvesting of fish populations drives genetically based shifts in body size and maturation. Frontiers in Ecology and the Environment, 11, 181-187.

Verhille, C. E., English, K. K., Cocherell, D. E., Farrell, A. P., \& Fangue, N. A. (2016). High thermal tolerance of a rainbow trout population near its southern range limit suggests local thermal adjustment. Conservation Physiology, 4, cow057.

Vornanen, M. (2016). The temperature dependence of electrical excitability in fish hearts. Journal of Experimental Biology, 219, 1941-1952.

Waldvogel, A.-M., Feldmeyer, B., Rolshausen, G., Exposito-Alonso, M., Rellstab, C., Kofler, R., ... Pfenninger, M. (2020). Evolutionary genomics 
can improve prediction of Species' responses to climate change. Evolution Letters, 4, 4-18.

Wang, T., \& Overgaard, J. (2007). Ecology. The heartbreak of adapting to global warming. Science (New York, N.Y.), 315, 49-50.

Ward, R. D., Jorstad, K. E., \& Maguire, G. B. (2003). Microsatellite diversity in rainbow trout (Oncorhynchus mykiss) introduced to Western Australia. Aquaculture, 219, 169-179.

Wieser, W. (1985). Developmental and metabolic constraints of the scope for activity in Young rainbow trout (Salmo Gairdneri). Journal of Experimental Biology, 118, 133-142.

Wood, C. C. (1995). Life history variation and population structure in sockeye Salmon. American Fisheries Society Symposium, 17, 195-216.

Zanuzzo, F. S., Bailey, J. A., Garber, A. F., \& Gamperl, A. K. (2019). The acute and incremental thermal tolerance of Atlantic cod (Gadus morhua) families under Normoxia and mild hypoxia. Comparative Biochemistry and Physiology -Part A: Molecular and Integrative Physiology, 233, 30-38.

Zhang, Y., Healy, T. M., Vandersteen, W., Schulte, P. M., \& Farrell, A. P. (2018). A rainbow trout Oncorhynchus mykiss strain with higher aerobic scope in Normoxia also has superior tolerance of hypoxia. Journal of Fish Biology, 92, 487-503.

How to cite this article: McKenzie DJ, Zhang Y, Eliason EJ, et al. Intraspecific variation in tolerance of warming in fishes.

J Fish Biol. 2020;1-20. https://doi.org/10.1111/jfb.14620 